\title{
HomeSense: Design of an ambient home health and wellness monitoring platform for older adults
}

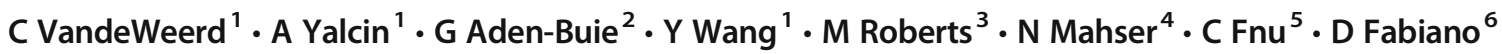

Received: 3 July 2019 / Accepted: 4 December 2019 / Published online: 3 July 2020

(C) The Author(s) 2020

\begin{abstract}
The unprecedented rise in the population of older adults and the number of seniors living with and managing chronic conditions are straining our institutional health care systems leading to reduced care quality and unmanageable cost increases. At the same time, an overwhelming majority of older adults express a strong desire to age in place in their communities. Ambient home sensing presents an opportunity to reduce healthcare costs by facilitating older adults' ability to age-in-place in more familiar, less restrictive, and less expensive environments. Further, ambient home sensing tools have the potential to extend the health care work force and enhance health care quality/outcomes by facilitating remote patient monitoring as well as early intervention and prevention against adverse events - all while catering to older adults' preference to live at home. Despite their potential, there is limited research at present about the benefits of ambient sensing systems installed in private homes, and older adults' response to them. This paper describes a pilot ambient home sensing project, HomeSense, actively deployed in the homes of older adults residing in The Villages, Florida.
\end{abstract}

Keywords Sensing $\cdot$ Health $\cdot$ Wellness $\cdot$ Aging $\cdot$ Smart home $\cdot$ Intelligent environments

\section{Introduction}

\subsection{Scope of the problem}

The growth in the number and proportion of older adults is unprecedented in the history of the United States [1] and the world [2]. According to the United Nations [3], the population of adults over the age of 60 has quadrupled from 205 million

C VandeWeerd

cvandewe@usf.edu

1 College of Industrial and Management Systems Engineering, The University of South Florida, Tampa, FL, USA

2 H. Lee Moffitt Cancer Center \& Research Institute, Tampa, FL, USA

3 School of Aging Studies, The University of South Florida, Tampa, FL, USA

4 College of Information Systems Decision Sciences, The University of South Florida, Tampa, FL, USA

5 Raymond James Financial, Tampa, FL, USA

6 College of Computer Science \& Engineering, The University of South Florida, Tampa, FL, USA in 1950 to almost 810 million in 2012 worldwide. This segment of the population is expected to double in size again reaching 2 billion persons (more than $20 \%$ of the world's population) by 2050 . In the US, the growth of older adults has kept pace with worldwide trends. Domestically, when the last baby boomer turns 65 in 2030, nearly 1 in every 5 Americans will be an older adult; and by 2050, more than 89 million Americans will be age 65 and older - double the number in 2010 - and almost $1 / 2$ of these persons (more than 40 million people) will have reached the age of 75 or above [1].

While seniors experience an unparalleled population boom, growth in younger cohorts is not matched. At the same time that the number of older adults (people 65+) is rising, the ratio of working age adults (people aged 15-64 years) to adults age 65 and older is expected to decline from 4.3 to 2.5 [4] resulting in a corresponding decline in the caregiver support ratio (the number of potential caregivers aged 45-64 for each person age 80 and older). As a result, this ratio is projected to fall from 7:1 in 2010 to $4: 1$ in 2030 and 3:1 by 2050 [5].

As people live longer, the prevalence of chronic conditions is also on the rise. At present, 70 million older adults are suffering from one chronic condition, and $2 / 3$ of adults over the age of 65 are suffering from 2 or more [6]. Chronic 
diseases result in a host of negative health consequences. People living with one or more chronic diseases often experience diminished quality of life, generally reflected by a long period of decline and disability associated with their chronic illness [7]. Chronic diseases affect a person's ability to perform important and essential activities such as activities of daily living (ADLs)-e.g. engaging in personal hygiene-and instrumental ADLs (IADLs)-e.g. shopping or managing finances, and lead to reduced social engagement, feelings of depression, and institutionalization [8-12]. The nation's expenditures for health care are already among the highest in developed countries. These costs are expected to increase by $55 \%$ over the next 10 years as chronic diseases affect growing numbers of older adults [13]. Today, more than $2 / 3$ of health care costs expended go to treating chronic illnesses, and in older adults, chronic disease treatment accounts for $95 \%$ of health care expenditures [14].

The rises in projected health care costs are unsustainable and call for improving the ways in which we detect and manage health [15]. Additionally, institutional health care systems are poorly prepared to meet the needs of the growing number of seniors, who have expressed a strong desire to "age in place" in their communities [16]. The CDC [17] has defined aging in place as "The ability to live in one's own home and community safely, independently, and comfortably, regardless of age, income or ability level." Aging in place offers significant benefits including reduction in health care costs through avoidance of institutionalization [18], improving quality of life [19], increasing independence [20], expanding/ maintaining social networks [21], and reducing risks for cognitive decline and adverse mental health [22].

Despite its considerable benefits, aging in place is not without risks. Without appropriate observation and supports, older adults may suffer negative consequences. Difficulties with home health or self-care tasks that go unrecognized and/or undetected can result in challenges with treatment plan compliance, risk for accident and injury, adverse health outcomes, increased morbidities and even death [23, 24]. Older adults living with multiple chronic conditions, living in rural environments and/or living alone are particularly vulnerable.

\subsection{Smart homes to facilitate aging in place}

Recently, ambient-assisted smart homes — residences equipped with ambient sensors and computing technologies that monitor the activities and well-being of occupants in their homes - are increasingly seen as facilitating innovative and supportive environments for enabling the healthy, safe, and independent aging plan desired by older adults [17, 24-34]. Technologies such as these offer a way to reduce healthcare costs by facilitating older adults' ability to age safely at home in less restrictive, less expensive environments. Smart homes can facilitate health and self-care activities by connecting older adults with primary and specialty health care providers, formal home health services, and informal caregivers, to facilitate early interventions and preventions for adverse health events, supporting effective long-term management of chronic conditions while aging in place. These technological solutions can also provide an additional layer of safety by continuously monitoring for life and health threatening situations - in effect, extending the health care workforce.

Domestically, programs such as the MAVHome at the University of Texas Arlington [35], The Aware Home at the Georgia Institute of Technology [36] and the Gator Tech Smart House at the University of Florida [37] have historically served as single-home-test-bed style environments. Internationally, the U-Health smart home project at POSTECH [38-40] integrates information from small sized medical body sensors [41] with other ambient sensors to assist older adults in their homes. Other programs including The Place Lab at the Massachusetts Institute of Technology [42], The Tiger Place project at the University of MissouriColumbia [43], the CASAS Smart Homes project at Washington State University [44] and the ORCATECH project of the Oregon Health and Science University [45] represent multi-unit smart home projects that are testing a variety of devices such as motion, floor, gait, bed, appliance, temperature, luminance, wearables, smartphone, web-portals, signaling devices, task aids and other smart/connected devices as a means to impact health and well-being across varying program targets. Despite their potential, understanding of the benefits of ambient home sensing and/or smart home systems on aging and health is limited and is still in infancy. To date, many projects are focused on limited user groups (i.e. persons with dementia), institutional settings (i.e. nursing homes), limited sensor types (i.e. contact and/or motion sensors) and/or are narrow in the scope of behaviors they monitor/target (i.e. gait, falls). Further, ability to perform long term health trend analyses, detect anomalies and generate alert signals in an emergency remains limited.

\subsection{Specific aim}

This paper will expand on the field of what is known about ambient-assisted smart homes for older adults by describing a novel and comprehensive ambient home-sensing platform, HomeSense, currently deployed in the homes of community residing older adults in The Villages, Florida.

\section{HomeSense: Ambient sensing platform for health monitoring}

HomeSense is an ambient health and wellness monitoring platform for community dwelling older adults living independently in their own home. It was developed by researchers in 
the CREATE Health Research Collaborative at the University of South Florida. Since its inception in the field in 2016, HomeSense has had 21 installations and collected more than 10 million hours of sensor data, with an average of 6500 sensor events per day per installation.

HomeSense supports healthy living for older adults who wish to "age in place" in their own home through: 1) daily activity visualization (i.e. the ability to see an older adult move about their home in real/near-real time) and summary visualization of activity trends over time (i.e. the ability to see and compare hygiene activities, sleep, or time spent outside the home at present, to levels yesterday, a week ago, a month ago) or 3 months ago; 2) periodic reporting for case management; 3 ) custom real-time notifications of behaviors that may signal adverse events (i.e. increased bathroom usage that may be an early indicator of a urinary tract infection); and 4) advanced analytics that allow us to examine long-term health and behavior trends that may signal system deficits, changes in habits, and/or risk or resilience over time.

In the rest of this section, we outline the system design philosophy and development, community testbed and participant recruitment, and capabilities and services of HomeSense that enable its use in basic and applied research in ambient health and wellness monitoring.

\subsection{Early system design and development}

Under supervision of the USF Institutional Board (PRO 00020982), HomeSense was developed in 4 phases. Using a community-based participatory research (CBPR) approach [46], Phase I involved targeted focus groups and one-on-one discussion with key informants $(N=68)$ such as older adults, family members (i.e. adult children and spouses), providers (i.e. primary and specialty care physicians, home health service agencies), informal caregivers, members of senior advocacy groups, and payers around system needs, preferences, and abilities in utilizing an ambient sensing platform to improve health and wellness for community residing seniors. The salient themes from these discussions clearly indicated that older adults are not open to the use of cameras and microphones as sensing/monitoring in their homes. A small number of participants $(N=4)$ — primarily adult children and care providers - also indicated concerns regarding data security. Overwhelmingly, the majority $(N=66)$ of all key informants in all classes preferred "passive" monitoring technologies which did not require interaction over "active-sensing" where participants would be required to wear or maintain/charge devices, expressing that passive technologies were less intrusive and likely to yield more consistent and robust results over time.

Informed by Phase I, Phase II involved the identification of activities of daily living and home-based behaviors that: 1) aligned with onset and progression of chronic conditions such as depression and heart disease that impacted older adults in late life; 2) could signal risk for adverse events such falls or social isolation; and 3) could signal resilience and/or protection from adverse events or disease progression.

Building on information learned in Phase I and II of the project, Phase III involved development and testing of the ambient sensing platform in a simulated home environment. Known as the "Living Lab" and supported through space donation of The Concordia Village in Tampa, CREATE Health maintains a senior living apartment within Concordia's seniorfocused residential housing complex in Tampa Bay. This facility includes a variety of housing options such as independent living apartments, short-stay rehab beds, assisted living, longterm nursing care and a specialized memory care unit. Comprised of a four-room apartment (one bedroom, one bathroom, living room and kitchen) the Living Lab serves as a testbed for technologies developed by CREATE Health prior to field use/deployment. In the first step of Phase III of the HomeSense project, example open/close (magnetic contact) sensors, passive infrared motion sensors, energy sensors, pressure sensors, water sensors and environmental sensors from a variety of manufactures were tested to identify devices that were most effective and reliable in capturing information related to the health and behavior domains identified as important in Phases I and II of the project (i.e. bathing and hygiene, feeding and nutrition, general routine, treatment plan compliance, social connectedness, sedentary behavior and sleep, toileting and TV use). Once complete, in Step 2, the long-term operation and functionality of the HomeSense system were tested and validated by a member of the research team who resided in the Living Lab full time for 8 weeks to ensure the system accurately detected the physical state of the living environment and correctly reflected activities of an occupant. Finally, in Step 3, seniors were invited to interact with the HomeSense system in the Living Lab environment and additional refinements to system function, layout, outcomes and visualizations were made based on their suggestions and feedback. In Phase IV, the fully developed HomeSense platform was deployed in the homes of older adults residing in The Villages.

\subsection{Community test bed and participant recruitment}

Core to understanding the factors for successful aging is the capacity to conduct pilot trials of novel interventions as well as large-scale, population studies in environments focused on the needs of aging populations. Located in central Florida, The Villages is an engaged community, focused on the needs of aging populations. To this end, USF's CREATE Health lab and The Villages have developed a unique partnership over the past 6 years, based upon a mutually recognized goal of improved health for The Villages and the advancement of knowledge about successful aging. In only 30 years, The Villages has become the largest planned older-adult 
community in the U.S. The Villages is home to more than 120,000 residents over the age of 55 and supports active lifestyles through more than 3000 resident clubs and 800 daily recreational activities. The Villages comprises a well-defined and socially cohesive population, representing older-adults from all 50 states and 14 different countries. Its neighborhood characteristics foster an environment rich with opportunity for social cohesion and social connectedness, while promoting successful aging and improved quality of life among its residents. While many residents report they are happier and more active than other U.S. communities, they share similar health challenges and medical conditions as all aging adults including cardiac and respiratory diseases, cancer and diabetes. The average Hierarchal Condition Category (HCC) prospective risk scores which reflect population health risk/likelihood of needing care for Medicare beneficiaries in Lake (0.97), Marion (0.98) and Sumter (0.92) counties (which comprise The Villages community) closely mirror the national average (1.00) [47] and given the similarities between The Villages residents and national samples, demonstrate that what is learned here has application for other communities.

Researchers from The CREATE Health lab have had a long-standing relationship with The Villages community that has included the provision of health education events and prior research collaborations [48-50]. These collaborations have resulted in the accumulation of a test-bank containing self-reported general health, demographic and contact information for more than 10,000 older adults. These individuals also expressly consented to being approached regarding participation in future studies examining health and wellness issues. Participants likely to meet the study's eligibility criteria (community dwelling, single adults over the age of 55 who speak English, and live in a pet free home that has internet access within The Villages, Florida were selected at random from amongst test-bank enrollees. They were initially contacted by phone about potential study participation. During this screening call, study aims and requirements were explained to participants, eligibility/enrollment criteria were tentatively verified, and an appointment was set for an inhome visit. During the in-home visit, study goals and needs were recapped, cognitive ability to make decisions was verified by a score of 24 or more on the Mini Mental Status Examination (a standardized survey for the measurement of cognitive health [51]), and informed consent was obtained.

In the 3 years since project inception, 21 older adults in single-resident homes have participated in the study, with 9 participants currently engaged. Study participation includes the completion of a comprehensive health assessment at enrollment, a willingness to have the passive home sensing system installed, and engagement in biweekly telephone screenings that collect on-going information about health using standardized assessment tools. Study participation is considered complete at 6 months of engagement, a target that has been reached by 19 of the participants ( 2 exited the study early as a result of relocation). Due to its varied benefits, many participants choose to continue with the study beyond the initial 6-month enrollment period and retained the sensor system in their homes even after the enrollment period. In total 15 participants have crossed the 1-year threshold, 7 have been with program 18 months or longer and 4 have stayed with the study since inception, providing 3 years of continuous home-based behavior data.

Demographics for study participants are shown in Table 1. Study participants range in age from 68 to 89 years, with a mean age at study start of 75.6 years. Six of the 21 participants are male, and 15 are female. Clinical characteristics for the sample are reported in Table 2. Participants reported an average of 2 co-morbid conditions at enrollment with 7 participants noting 3 or more comorbidities. Co-morbid conditions varied by participant and included diseases such as hypertension, diabetes, arthritis, osteoporosis, hearing impairment, depression, early Alzheimer's and Parkinson's disease. Not surprisingly, participants reported taking an average of 3.63 medications at the time of study enrollment, ranging from 0 to 8 . High average Mini Mental Status Exam scores indicate good cognitive health within the sample. $33 \%$ of participants were found to be at high risk for nutritional deficits, and $38 \%$ scored as at risk for alcohol misuse as measured by the Nutritional Screening Checklist and Alcohol Use Disorders Identification Test respectively. Scores on the Desmond Fall Risk Questionnaire, ECOG and Timed Up and Go Tests indicated mobility risks in several program participants (for additional details on screening tools, see Section 3). No concerns regarding privacy were raised by participants at the time of enrollment and capture rate (the rate of participants initially contacted about study participation versus those who ultimately met screening criteria and agreed to participate in the study) ranged between 30 and $40 \%$.

Table 1 Participant Demographics

\begin{tabular}{ll}
\hline Age (mean \pm SD) & $75.6 \pm 4.8$ \\
\hline $\begin{array}{l}\text { Gender (\% women) } \\
\text { Race/Ethnicity (\%) }\end{array}$ & 71 \\
White & 100 \\
Education (n, \%) & \\
High school & $3(14)$ \\
Some college & $3(14)$ \\
Associate's degree & $2(10)$ \\
Bachelor's degree & $8(38)$ \\
Master's degree & $3(14)$ \\
PhD/MD & $2(10)$ \\
\hline
\end{tabular}


Table 2 Participant Clinical Characteristics

\begin{tabular}{llrr}
\hline & M \pm SD & Min. & Max. \\
\hline \# of medications & $3.6 \pm 2.6$ & 0 & 8 \\
\# of comorbid conditions $^{2}$ & $2.0 \pm 1.6$ & 0 & 6 \\
MMSE $^{\mathrm{a}}$ & $29.7 \pm 0.7$ & 27 & 30 \\
MCFSI $^{\mathrm{b}}$ & $1.7 \pm 1.3$ & 0 & 4 \\
MHI-5 $^{\mathrm{c}}$ & $89.1 \pm 9.7$ & 64 & 100 \\
FSSQ $^{\mathrm{d}}$ & $4.3 \pm 0.6$ & 0 & 4 \\
PSQI $^{\mathrm{e}}$ & $6.2 \pm 2.4$ & 3 & 11 \\
TUG $^{\mathrm{f}}$ & $9.3 \pm 4.1$ & 6 & 18 \\
ECOG $^{\mathrm{g}}$ & $0.3 \pm 0.6$ & 0 & 2 \\
Desmond Fall Risk Questionnaire $^{\mathrm{h}}$ & $2.5 \pm 2.2$ & 0 & 8 \\
AUDIT-C $^{\mathrm{i}}$ (\% alcohol misuse) & $38 \%$ & & \\
Nutrition Screening $^{\mathrm{j}}$ (\% High Risk) & $33 \%$ & & \\
\hline
\end{tabular}

Note: ${ }^{\mathrm{a}} \mathrm{MMSE}=$ Mini Mental State Examination [51]. ${ }^{\mathrm{b}} \mathrm{MCFSI}=$ MailIn Cognitive Function Screening Instrument [52]. ${ }^{\mathrm{c}}$ MHI-5 = Mental Health Inventory-5 item [53]. ${ }^{\mathrm{d}}$ FSSQ = Duke-UNC Functional Social Support Questionnaire [54]. ${ }^{\mathrm{e}} \mathrm{PSQI}=$ Pittsburgh Sleep Quality Index [55]. $.^{\mathrm{f}} \mathrm{TUG}=$ Timed "Up and Go" Test [56]. ${ }^{\mathrm{g}} \mathrm{ECOG}=$ Eastern Cooperative Oncology Group Performance Status [57]. ${ }^{\mathrm{h}}$ Desmond Fall Risk Questionnaire [58]. ${ }^{\mathrm{i}}$ AUDIT-C $=$ Alcohol Use Disorders Identification Test [59]. ${ }^{j}$ Nutrition Screening $=$ Nutritional Health Checklist [60]

\subsection{System architecture}

As part of HomeSense, wireless sensing devices (i.e. magnetic contact sensors, passive infrared motion sensors, energy sensors, pressure sensors, water sensors and environmental sensors) are placed throughout a home in a standard array by members of the CREATE Health research team. An example of such a deployment is shown in Fig. 1. These devices collect information such as room entry/exit, electrical consumption/ use of targeted devices (e.g. microwave, TV), luminance, humidity, temperature, toilet usage, location of occupant, and behavior (e.g., fridge opening) where appropriate. While the number of sensing devices varies by the number of rooms in a home, most deployments utilize between 16 and 20 sensing devices to capture $90 \%$ home coverage. Houses are mapped at the consent/enrollment visit to facilitate seamless, efficient, and unobtrusive integration into home environments, and systems can be deployed, verified, and rendered fully operational within 14 days.

As shown in Fig. 2, an array of networked wireless Z-Wave devices are installed in each house. A Raspberry Pi connected to the internet acts as a remote gateway (serving as a small computing device) and monitors the Z-Wave communication network. It stores and relays relevant events and information to USF's Health Insurance Portability and Accountability Act (HIPAA) compliant secure server cluster. In case of internet outages, data from the homes is stored locally on the gateways and sent on to the main server once connectivity is restored.
Data that comes in to the main server from participants' homes is permanently stored and backed up in relational databases which support administrative tasks such as sensor configuration, device tracking, and notification set up. A collection of data analytics tools continuously process the collected data and support the HomeSense services including alerts and notifications, case management reporting, participant communications, and the web-enabled user interfaces for participants and authorized caregivers which are further discussed in subsequent sections.

\subsection{Web-enabled user interfaces}

Sensor data is sent from remote gateways in the participants' homes to the main-server where it is processed to facilitate daily activity monitoring and summary, and identification of changes over time. A variety of password-protected user profiles (i.e. participant, family member, health provider, paid case manager, and administrator) are available within the HomeSense web portal. These profiles are fully customizable and ensure the user/older-adult maintains control of what information they do or do not share and with whom. Once logged in, a customizable landing page provides users a brief summary of daily activity and home-based information from the prior day (i.e. sleep and wake times, home temperature, time spent outside the home); and a daily activity visualization screen shown in Fig. 3 facilitates the ability to see an older adult as they move about their home. Developed in conjunction with user feedback collected in Phase I and III of the HomeSense development process, a refined set of sensor data is shown across user classes (i.e. informal caregiver versus paid case manager) to maximize utility and ease of use for the target user group. Additionally, processed data is used to create customizable tables designed to summarize change over time. By default, data points such as sleep or bathroom usage are shown comparing today's behaviors to $1,7,30$ and 90 days prior.

We have observed that interfaces such as the daily and summary activity visualizations can help alleviate caregiver burden and engage older adults, encouraging them to be more actively involved in management of their health. Utilizing this tool, older adults can gauge parameters such as the amount of time they spend sedentary and the number of times they have missed their medication and actively take intervention steps to change and improve their overall health. For caregivers, being able to visualize care recipients at home while out shopping or engaged in other activities, results in increased independence and lowers burden since they can be outside of the home but still be aware of what their care recipient is doing. This increased freedom can increase social engagement, reduce loneliness and social isolation and lead to increases/improvements in mental and physical health long term. 


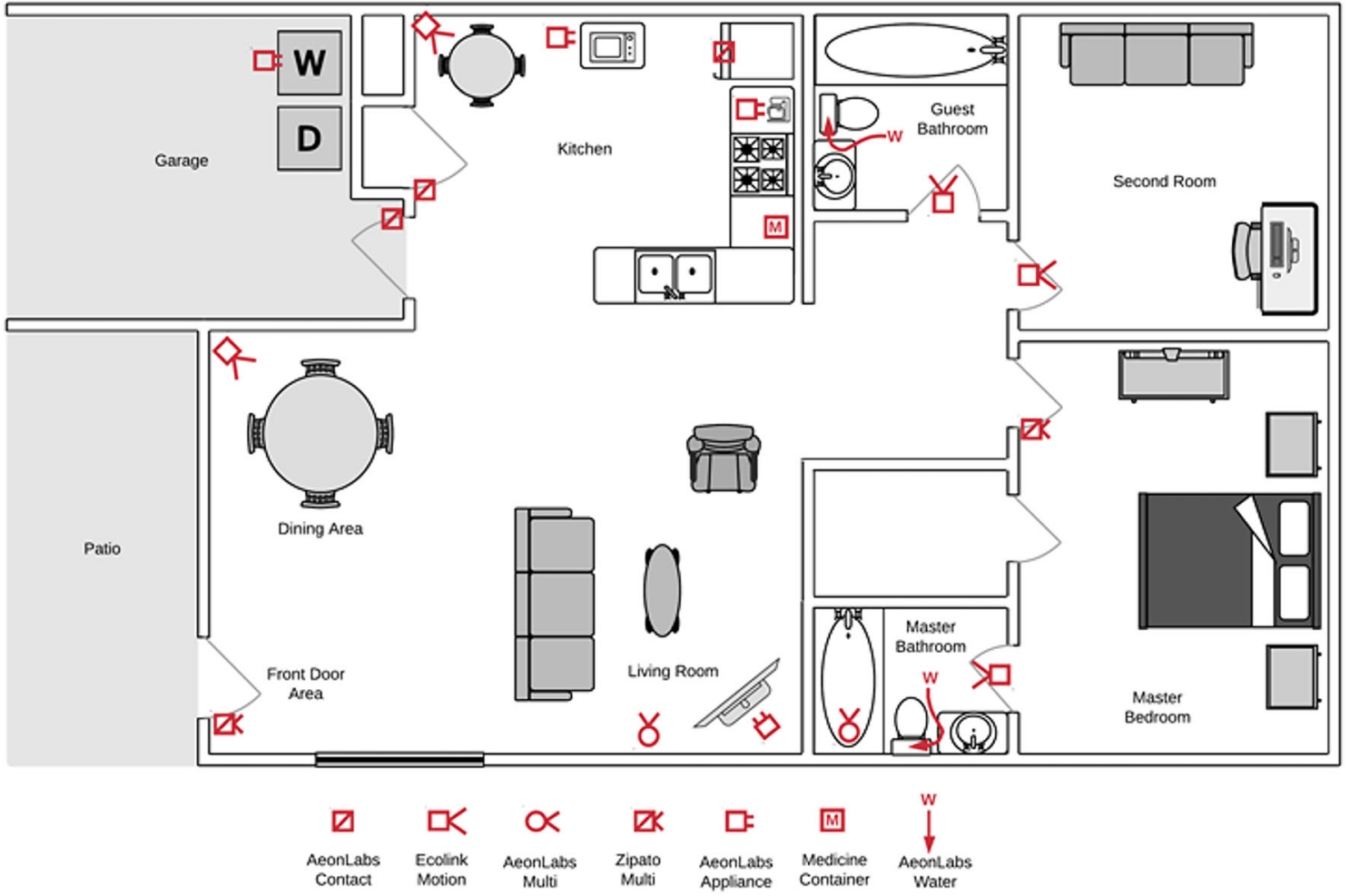

Fig. 1 Example sensor deployment showing ambient sensors placed throughout the home

\subsection{Case management reporting}

Reporting tools for case managers shown in Fig. 4 enable paid health providers to readily identify and prioritize clients in need of support/touch points. These reports allow case managers to easily identify frequency and changes in activities such as toileting, hygiene, sleep, physical activity and nutritional behaviors. Among other examples, use of these reporting tools can help case managers track and identify patients who have missed medications, failed to rise or who have experienced changes in their sleep and/or activity patterns that may signal the onset of, or risk for adverse events. Case managers supported by computer-aided decision making tools can identify patients outside of their routines who may be in need of intervention or services - all without the need to manually review data patterns and/or physically check in with or on patients across great distances who may not be in need of support. As such, HomeSense serves as a tool to strategically

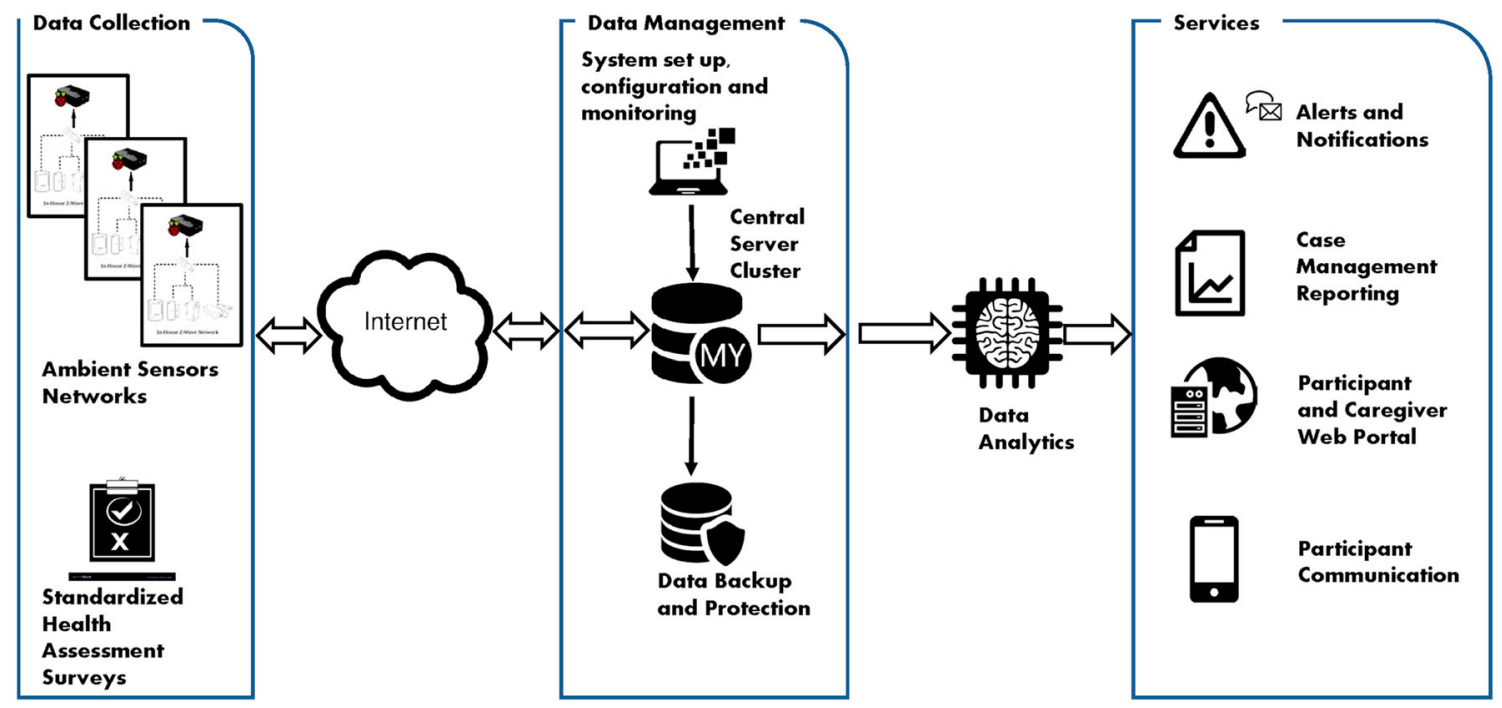

Fig. 2 HomeSense system architecture comprised of data collection, data management and participant services 


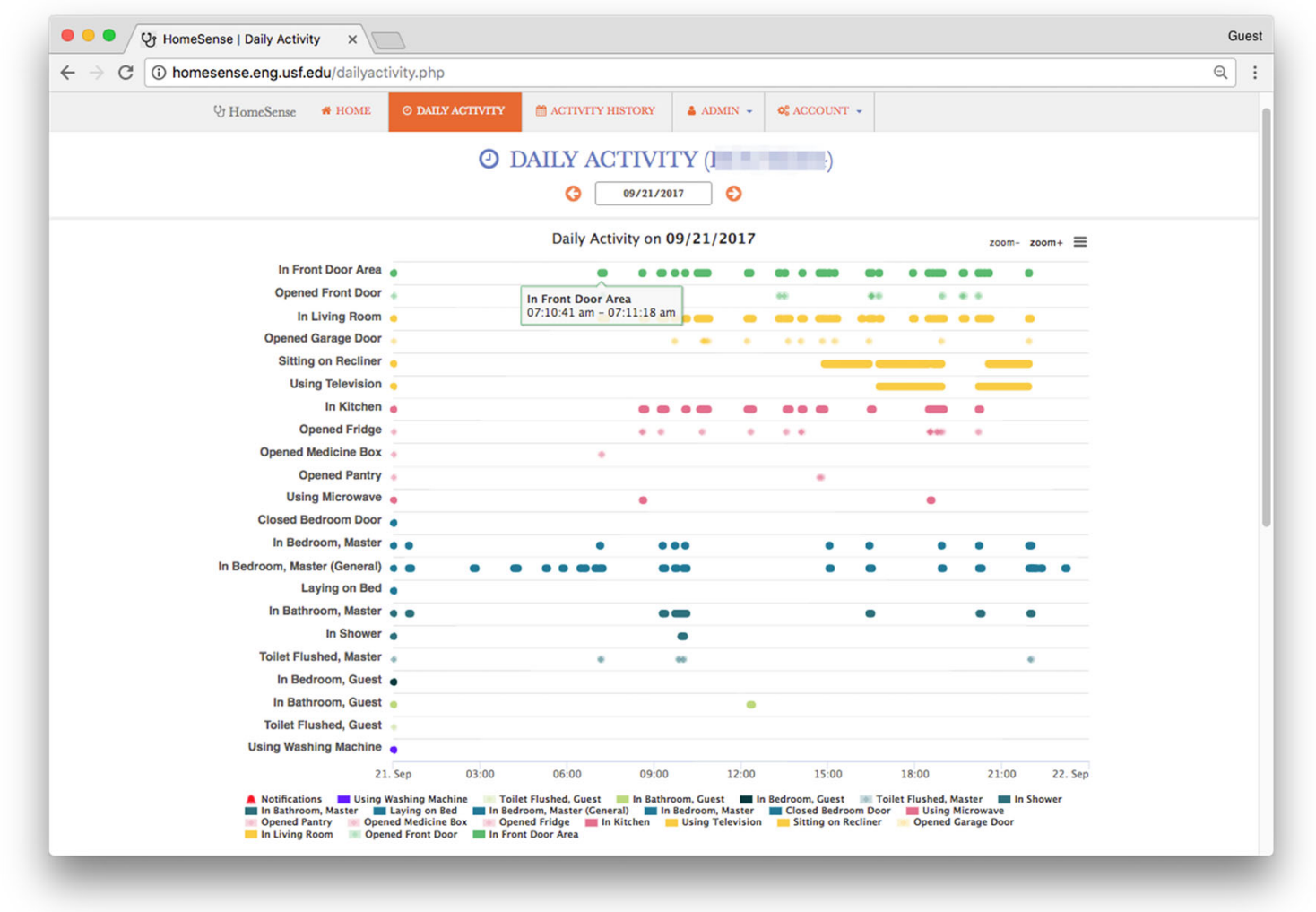

Fig. 3 Sample Daily and Summary Activity Visualization showing a participant as s/he move about their home and engage in various Activities of Daily Living

extend provider reach and expand caseloads in ways that still identify and prioritize patients in need of additional services while respecting the privacy of those who don't.

HomeSense data can also be used to examine differences in home-based behaviors over time across age and clinical subgroups to facilitate case managers' understanding of the ways in which advancing age and/or clinical conditions may impact routine and quality of life over time, and to facilitate service and treatment planning. Using Welch's t-test for unequal sample sizes and the Wilcoxon Rank Sum Test for continuous variables, Table 3 identifies home-based activity data over 180 days for the 15 program participants enrolled in the study 12 months or more. Results indicate significant differences in the amount of time spent doing laundry $(70+=80 \mathrm{mins} ;<70=$ 41mins; $p=.04$ ) and in the average number of sleep disruptions experienced over-night $(70+=0.8 ;<70=0.5 ; \mathrm{p}=.04)$. Given the negative impacts of sleep disruption on physical and mental health [61], reasons for increased sleep disruption in those 70+ should be explored, and where appropriate, medications or lifestyle changes to better control factors such as co-morbid conditions that may improve sleep patterns should be encouraged to preserve long term health and quality of life. While potentially an artifact of machine run times, increased time spent in routines such as doing laundry may also be an early cue that additional help may be needed at home and options for supplements such as housekeeping services may reduce burdens and keep older adults living longer at home.

Differences in home-based behaviors are also seen across clinical sub-groups and can be used as a tool to enhance treatment planning and quality of life. For example, preliminary results in Table 3 illustrate that those with osteoporosis spend less time in bed (osteoporosis $=7.3 \mathrm{~h} /$ day; no osteoporosis = $8.4 \mathrm{~h} /$ day; $p=.05$ ) and experience a greater number of sleep disruptions (osteoporosis $=1.4$ /evening; no osteoporosis $=0.5$ / evening; $p=.04)$. Additionally, people with osteoporosis spend more time using their televisions (osteoporosis $=3.9 \mathrm{~h} /$ day; no osteoporosis $=2.5 \mathrm{~h} /$ day; $\mathrm{p}=.04$ ) and more time away from home (osteoporosis $=4.5 \mathrm{~h} /$ day; no osteoporosis $=3.6 \mathrm{~h} /$ day; $p=.03$ ). These findings are consistent with commonly reported disease symptoms such as frequent pain and trouble getting comfortable [62] which can lead to behaviors such as rising from bed during the night to watch TV - adversely impacting sleep quality, sleep consistency and the body's ability to produce essential hormones such as melatonin which are believed to help regulate sleep and reduce free radicals in the body, leading to poorer health over time [63]. For patients such as these, specialized pain clinics and physical therapy may be helpful in increasing night time comfort; additionally, dietary supplements such as synthetic melatonin may be helpful in re-regulating the sleep cycle. 
Fig. 4 Example HomeSense Summary Reports for Technology Enhanced Case Management showing daily and weekly key metrics related to hygiene, nutrition, bathroom usage and daily activities

\section{HomeSense Summary Report}

House 8 | Report was generated on 2019-04-10 at 06:21 PM

Weekly Table

\begin{tabular}{|c|c|c|c|c|c|}
\hline & $\begin{array}{l}\text { Historical } \\
\text { Average }\end{array}$ & $\begin{array}{c}\text { Mar 20, } \\
\text { Wednesday }\end{array}$ & $\begin{array}{c}\text { Mar 27, } \\
\text { Wednesday }\end{array}$ & $\begin{array}{c}\text { Apr 03, } \\
\text { Wednesday }\end{array}$ & $\begin{array}{c}\text { Apr 10, } \\
\text { Wednesday }\end{array}$ \\
\hline \multicolumn{6}{|l|}{ Hygiene } \\
\hline Time Spent In Shower & $52 \mathrm{~min}$ & $38 \mathrm{~min}$ & $1 \mathrm{hr} 16 \mathrm{~min}$ & $36 \mathrm{~min}$ & $58 \mathrm{~min}$ \\
\hline $\begin{array}{l}\text { Time Using Washing } \\
\text { Machine }\end{array}$ & $1 \mathrm{hr} 10 \mathrm{~min}$ & Omin & $26 \min$ & $2 \mathrm{hr} 10 \mathrm{~min}$ & $2 \mathrm{hr} 6 \min$ \\
\hline \multicolumn{6}{|l|}{ Nutrition } \\
\hline Fridge Opening(s) & 31.8 & 27 & 36 & 33 & 31 \\
\hline Pantry Opening(s) & 43.5 & 41 & 46 & 40 & 47 \\
\hline Microwave Usage(s) & 0.5 & 0 & 1 & 1 & 0 \\
\hline Toaster Usage(s) & 1.8 & 1 & 2 & 2 & 2 \\
\hline Time Spent In Kitchen & $6 \mathrm{hr} 46 \mathrm{~min}$ & $6 \mathrm{hr} 14 \mathrm{~min}$ & $7 \mathrm{hr} 9 \min$ & $6 \mathrm{hr} 59 \mathrm{~min}$ & $6 \mathrm{hr} 43 \mathrm{~min}$ \\
\hline \multicolumn{6}{|l|}{ Bathroom Usage } \\
\hline $\begin{array}{l}\text { Time Spent In Master } \\
\text { Bathroom }\end{array}$ & $5 \mathrm{hr} 24 \mathrm{~min}$ & $7 \mathrm{hr} 15 \mathrm{~min}$ & $4 \mathrm{hr} 9 \min$ & $4 \mathrm{hr} 39 \mathrm{~min}$ & $5 \mathrm{hr} 32 \mathrm{~min}$ \\
\hline $\begin{array}{l}\text { Time Spent In Guest } \\
\text { Bathroom }\end{array}$ & $1 \mathrm{hr} 48 \mathrm{~min}$ & $1 \mathrm{hr} 59 \mathrm{~min}$ & $1 \mathrm{hr} 54 \mathrm{~min}$ & $1 \mathrm{hr} 28 \mathrm{~min}$ & $1 \mathrm{hr} 51 \mathrm{~min}$ \\
\hline \multicolumn{6}{|l|}{ Daily Activities } \\
\hline $\begin{array}{l}\text { Time Spent In Living } \\
\text { Room }\end{array}$ & $17 \mathrm{hr} 15 \mathrm{~min}$ & $17 \mathrm{hr} 52 \mathrm{~min}$ & $20 \mathrm{hr} 32 \mathrm{~min}$ & $15 \mathrm{hr} 11 \mathrm{~min}$ & $15 \mathrm{hr} 23 \mathrm{~min}$ \\
\hline Time Spent Using TV & $41 \mathrm{hr} 4 \mathrm{~min}$ & $44 \mathrm{hr} 47 \mathrm{~min}$ & $42 \mathrm{hr} 36 \mathrm{~min}$ & $37 \mathrm{hr} 52 \mathrm{~min}$ & $39 \mathrm{hr} 3 \mathrm{~min}$ \\
\hline Bed Time* & 08:39 PM & 08:25 PM & 08:56 PM & 08:33 PM & 08:44 PM \\
\hline Wake up Time* & 07:44 AM & 07:38 AM & 07:34 AM & $07: 50 \mathrm{AM}$ & 08:07 AM \\
\hline Time Spent In Bed ${ }^{*} \dagger$ & $75 \mathrm{hr} 52 \mathrm{~min}$ & $74 \mathrm{hr} 16 \mathrm{~min}$ & $72 \mathrm{hr} 20 \mathrm{~min}$ & $77 \mathrm{hr} 45 \mathrm{~min}$ & $79 \mathrm{hr} 8 \mathrm{~min}$ \\
\hline Sleep Distruption* & 4.5 & 6 & 6 & 4 & 2 \\
\hline Time Spent Outside ${ }^{\star} \dagger$ & $37 \mathrm{hr} 34 \mathrm{~min}$ & $33 \mathrm{hr} 13 \mathrm{~min}$ & $41 \mathrm{hr} 23 \mathrm{~min}$ & $40 \mathrm{hr} 23 \mathrm{~min}$ & $35 \mathrm{hr} 15 \mathrm{~min}$ \\
\hline
\end{tabular}

\subsection{Notifications: A mechanism for health interventions in the short term}

The main goal of the HomeSense system is to help seniors age safely in place while optimizing their health and wellness. To do this, HomeSense strategically deploys standard sensor arrays to facilitate data collection in 8 health domains including feeding/nutrition, bathing/hygiene, toileting, sedentary behavior and sleep, general routine, treatment plan compliance, social connectedness and TV usage. Layered on top of this is a fully customizable notification system that facilitates web and mobile alerting to notify interested parties of changes in physical activity, sleeping habits, time spent outside the home, sedentary behavior, nutritional habits, socialization patterns, toileting or hygiene patterns in real/near-real time.
Additionally, the notification system can be set up to send alerts when participants are in the bathroom too long, if they exit their home late at night, if they altered/missed their medications, if they failed to rise, and/or if they failed to fulfill obligations at home. These notifications are either rule-based (e.g., notify if an occupant exits the home after $11 \mathrm{pm}$; notify if an occupant has not gotten up by $11 \mathrm{am}$ ) or based on understanding of previously learned/observed participant behavior (i.e. notify if an occupant has a $20 \%$ increase in sedentary behavior or toilet usage). Once triggered, notifications appear on the daily activity visualization screen, alerting users that something is outside the norm. In addition, a screenshot of the daily activity screen and an explanation of the notification, as shown in Fig. 5, is sent to users via email facilitating easy access and understanding without the need for additional login 
Table 3 Summary of Continuously Assessed Indicators (180 days)

\begin{tabular}{|c|c|c|c|c|c|c|c|}
\hline \multirow[b]{2}{*}{ Health Domain } & \multirow{2}{*}{$\begin{array}{l}\text { All Participants } \\
(N=15) \\
\text { Mean } \pm \text { SD }\end{array}$} & \multicolumn{2}{|l|}{ Age Cohorts } & \multirow[b]{2}{*}{$P^{5}$} & \multicolumn{2}{|c|}{ Osteoporosis Cohort } & \multirow[b]{2}{*}{$P^{6}$} \\
\hline & & $\begin{array}{l}\text { Less than } 70 \\
(N=8) \\
\text { Mean } \pm \mathrm{SD}\end{array}$ & $\begin{array}{l}70+ \\
(N=7) \\
\text { Mean } \pm \text { SD }\end{array}$ & & $\begin{array}{l}\text { Yes } \\
(N=3) \\
\text { Mean } \pm \text { SD }\end{array}$ & $\begin{array}{l}\text { No } \\
(N=12) \\
\text { Mean } \pm \text { SD }\end{array}$ & \\
\hline \multicolumn{8}{|l|}{ Hygiene } \\
\hline Time spent in shower ${ }^{1}$ & $7.8 \pm 6.1$ & $7.9 \pm 5.9$ & $7.7 \pm 6.8$ & 0.95 & $8.1 \pm 11.6$ & $7.8 \pm 4.7$ & 0.93 \\
\hline Time using washing machine ${ }^{2}$ & $58.8 \pm 37.8$ & $41.3 \pm 20.3$ & $79.8 \pm 43.4$ & $0.04 *$ & $47.6 \pm 29.7$ & $61.7 \pm 39.9$ & 0.59 \\
\hline \multicolumn{8}{|l|}{ Nutrition } \\
\hline Fridge opening $(\mathrm{s})^{3}$ & $17.5 \pm 9.8$ & $19.2 \pm 9.5$ & $15.6 \pm 10.4$ & 0.49 & $11.9 \pm 10.1$ & $18.9 \pm 9.6$ & 0.28 \\
\hline Pantry opening $(s)^{3}$ & $5.4 \pm 5.6$ & $6.6 \pm 6.4$ & $4.3 \pm 4.9$ & 0.47 & $1.3 \pm 0.8$ & $6.5 \pm 5.8$ & 0.16 \\
\hline Microwave usage $^{3}$ & $1.9 \pm 1.6$ & $1.7 \pm 1.5$ & $2.2 \pm 1.8$ & 0.57 & $2.1 \pm 1.8$ & $1.9 \pm 1.6$ & $0.04 *$ \\
\hline Toaster usage $^{3}$ & $1.2 \pm 1.6$ & $1.3 \pm 2.0$ & $1.0 \pm 0.7$ & 0.83 & $0.4 \pm 0.3$ & $1.5 \pm 1.8$ & 0.46 \\
\hline Time spent in kitchen ${ }^{4}$ & $2.6 \pm 1.3$ & $2.5 \pm 0.9$ & $2.6 \pm 1.7$ & 0.93 & $2.6 \pm 0.5$ & $2.6 \pm 1.5$ & 0.99 \\
\hline \multicolumn{8}{|l|}{ Bathroom Usage } \\
\hline Time spent in master bathroom ${ }^{1}$ & $60.8 \pm 41.1$ & $68.3 \pm 47.7$ & $52.3 \pm 33.6$ & 0.48 & $41.5 \pm 18.8$ & $65.6 \pm 44.3$ & 0.38 \\
\hline Time spent in guest bathroom ${ }^{1}$ & $14.4 \pm 19.5$ & $7.5 \pm 6.7$ & $21.3 \pm 25.8$ & 0.20 & $37.0 \pm 34.6$ & $8.3 \pm 7.7$ & 0.29 \\
\hline \multicolumn{8}{|l|}{ Daily Activities } \\
\hline Time spent in living room ${ }^{4}$ & $2.8 \pm 1.2$ & $3.3 \pm 1.3$ & $2.3 \pm 1.0$ & 0.14 & $2.0 \pm 1.3$ & $3.0 \pm 1.2$ & 0.19 \\
\hline Time spent using $\mathrm{TV}^{4}$ & $3.6 \pm 3.1$ & $2.3 \pm 2.8$ & $5.3 \pm 2.9$ & 0.79 & $3.9 \pm 3.2$ & $2.5 \pm 2.9$ & $0.04 *$ \\
\hline Sleep disruption ${ }^{4}$ & $0.7 \pm 0.7$ & $0.5 \pm 0.4$ & $0.8 \pm 0.9$ & $0.04 *$ & $1.4 \pm 1.3$ & $0.5 \pm 0.3$ & $0.04 *$ \\
\hline Time spent in bed ${ }^{4}$ & $8.1 \pm 2.2$ & $8.0 \pm 1.9$ & $8.3 \pm 2.6$ & 0.79 & $7.3 \pm 4.4$ & $8.4 \pm 1.4$ & $0.05 *$ \\
\hline Time spent outside ${ }^{4}$ & $3.8 \pm 3.1$ & $4.5 \pm 3.3$ & $3.0 \pm 2.6$ & 0.38 & $4.5 \pm 5.9$ & $3.6 \pm 2.4$ & $0.03 *$ \\
\hline
\end{tabular}

Note: ${ }^{1}=$ Time $($ minutes $) /$ day $^{2=}$ Time (minutes) $/$ week $^{3}=$ count $^{4}=$ Time (hours) $/$ day ${ }^{5}=\#$ of disruptions $\left(20+\right.$ minutes out of bed)/evening ${ }^{5}$ Wilcoxon Rank Sum Test ${ }^{6}$ Welch's Independent Sample t-test

or software. Notifications can be sent to select users (e.g. changes in hygiene or sleep habits to health care providers, late-night exist seeking to a child/informal caregiver) and/or to multiple users (e.g. changes in nutritional habits to adult children and health care providers) facilitating strategic communication across occupants' social/health networks.

\subsection{Communication with participants}

An important research component of an ambient home health and wellness monitoring platform is the ability to recognize events relevant to health and wellness. Algorithms developed for such purposes require ground truth to be validated. Traditional methods like manual activity logging unnecessarily burden users and are ineffective [64]. As a result, we have developed a mobile app which allows us to send custom questions to, and receive answers from our study participants in real time, allowing us to validate the algorithms with minimal burden. An example question sent to a participant regarding the time they went to bed is shown in Fig. 6. We have successfully used this mobile app to validate activity detection algorithms involving four activities involving leaving and returning home, and going to bed at night and waking up in the morning. During a 5 month study, 518 questions (236 true negatives) were sent to two participants who responded to $72.2 \%$ of the questions. Their responses demonstrated $90 \%$ and $98 \%$ accuracy with no significant variation by question type or participant. $88 \%$ of the true negative questions were responded to as a "No, I did not perform this activity in this time range" with no significant variation by participant showing strong evidence that there was no social desirability or habituation bias in the validation process [65]. This tool can also be harnessed to administer well-established, short, high salience instruments such as the Patient Health Questionaire2 , a screening tool for depression symptomology [66] to participants in real time to explore a variety of health outcomes such as mental well-being.

\subsection{Data visualization for understanding health and wellness related behaviors}

An effective way to explore trends in daily activity patterns using sensor data is through data visualization. To this end, we developed a visualization dashboard, HomeSense-Dash, which contains dynamic and flexible sensor data visualizations for varying time durations and sensor devices. The example in Fig. 7 highlights select sensors which represent the general daily activity of a participant over a $24-\mathrm{h}$ period. The 
Fig. 5 Automatically generated notification e-mail for medication noncompliance based on activities observed by HomeSense

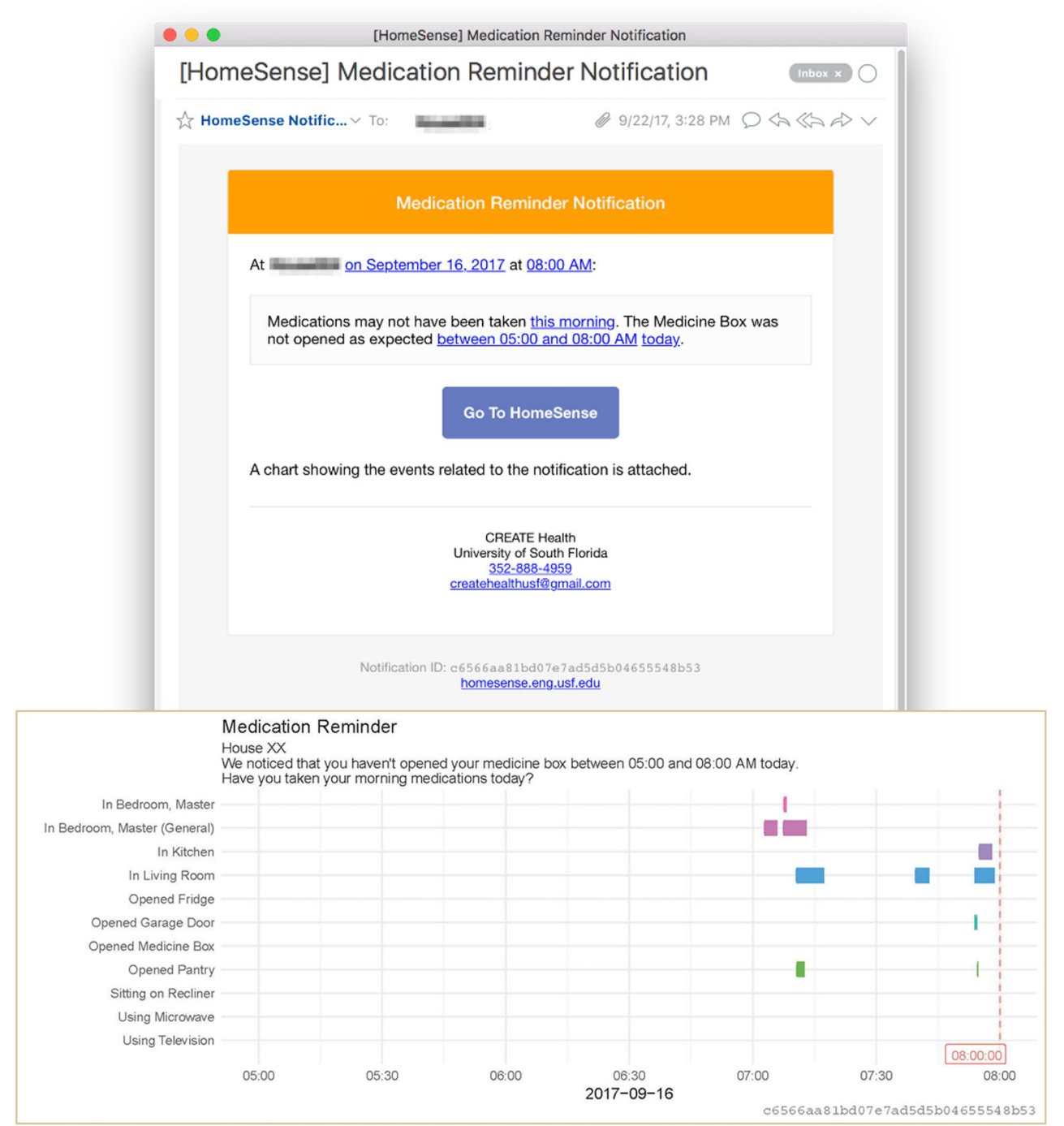

participant wakes up around 6:00 am noted by the disengagement of the pressure mat under his bed. After brief activity in the living room, kitchen and bathroom observed by the PIR motion sensors, he leaves the house returning again around noon observed using contact sensors placed on doors leading to the outside and absence of motion inside the home. After a brief period in the house, presumably for lunch based on the level of activity in the kitchen observed using motion sensors and interactions with the fridge and pantry observed by contact sensors placed on fridge and pantry doors, the participant again leaves returning home around 3:00 pm and settling in for the evening. In the evening, he spends time in the living room on his recliner observed using a pressure mat under the chair cushions and in the study watching TV observed using smart switches monitoring energy usage. He also interacts with the fridge and pantry around 8:00 pm presumably for dinner, and he eventually goes to bed around 10:00 pm. Throughout the day, the participant's toilet usage is observed using motion sensors in the bathroom and water sensors placed in the toilet reservoir.

HomeSense-Dash is also used for more detailed exploration of specific activities. For example, Fig. 8 shows a polar graph of the times of day one of our participants opens their medicine cabinet over several months. The axis represent midnight, 6:00 am, noon, and 6:00 pm similar to a 24-h analog clock. The participant takes medication 3 times a day: morning, late afternoon and evening. It is clear that compliance with the morning and late afternoon medicine routine exhibits much greater time variability than the medication routine in the evening time frame. This kind of data can be very informative in identifying additional targets for utilizing tools such as care plans and health education to increase compliance with proper medication routines. In cases where patients are managing time-sensitive medications like those for blood pressure, this reporting offers significant potential to assist in the maintenance and achievement of good health over time. 


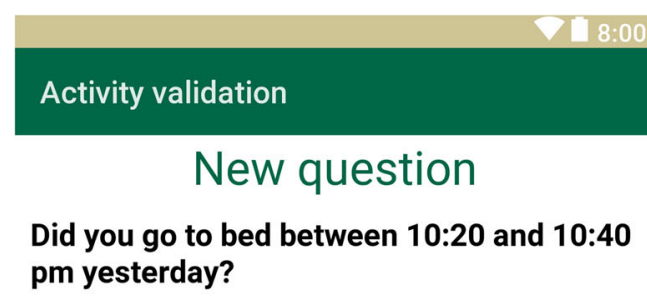
Yes, I performed the activity
in this time range

No, I did not perform the activity in this time range
I am not certain/I do not recall

SUBMIT

We appreciate your feedback.

\section{$\triangleleft$}

\section{O}

\section{$\square$}

Fig. 6 Mobile app to communicate with participant through simple Q\&As

In addition to exploring individual sensor data, we have developed algorithms which combine information from individual sensors to extract higher level information such as when participants leave and return home, what time they go to sleep and wake up, how much time they spend in their home engaged in sedentary activities such as watching TV, and how active they are moving about in their home [65]. Visualizations based on the outputs of such algorithms elucidate participants' daily routines at home and reveal patterns that remain stable as well as vary over time. For example, Figs. 9 and 10 show participant status as active, sedentary, in-bed and out-of-home over a 3 month period for two participants (A and B). The time durations during which the sensor system could not estimate the status of the participant is categorized as unobservable.

Figure 9 shows that Participant A exhibits stable activity patterns over time. The participant tends to leave their home each day in the late morning and early afternoon and usually returns home before $5 \mathrm{pm}$; we note that the participant was away from home on the evening of Feb 16. Sleep patterns for this participant are also fairly routine and stable. Typically the participant wakes up around 7 am and goes to bed around $10 \mathrm{pm}$. On January 10th, February 24th and February 27th the participant appears to have had more restless sleep - and has spent the early morning hours out of bed. As reported in their biweekly health assessments (see Section 3) these dates coincide with worry for a family member (Jan 10th) and onset and worsening of a cold (February 24 and 27th), illustrating the ways in which stress and physical body strain change behaviors at home.

Examining home-based behaviors across participants also yields potential for significant insights around the impact of disease conditions and medications on homebased behavior patterns, Fig. 10 demonstrates homebased activity patterns for Participant B over the same time period. The participant generally leaves home twice a day - once around lunch time and again in the late

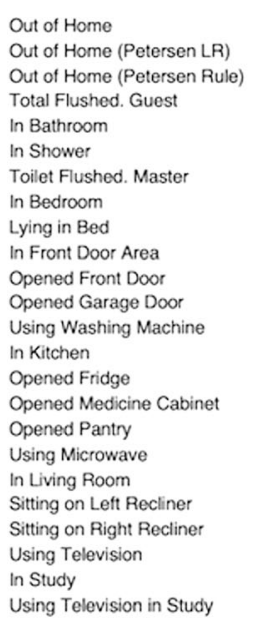

Out of Home (Petersen LR) Out of Home (Petersen Rule) Total Flushed. Guest

In Bathroom

In Shower

Toilet Flushed. Master

In Bedroom

Lying in Bed

In Front Door Area

Opened Front Door

Opened Garage Door

Using Washing Machine

In Kitchen

Opened Fridge

Opened Medicine Cabinet

Opened Pantry

Using Microwave

In Living Room

Sitting on Left Recliner

Sitting on Right Recliner

Using Television

In Study

Using Television in Study

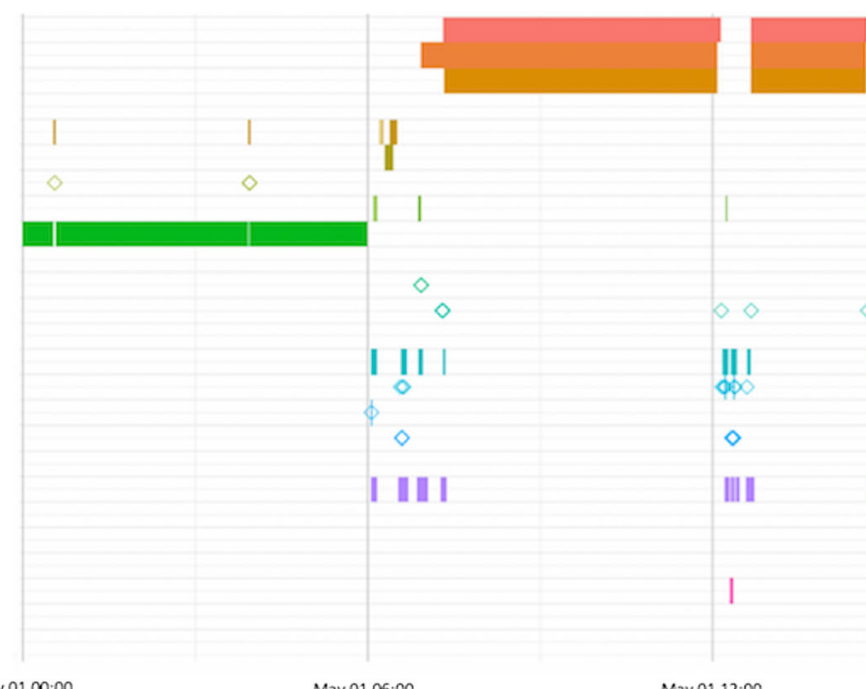

May 01 06:00

May 01 12:00

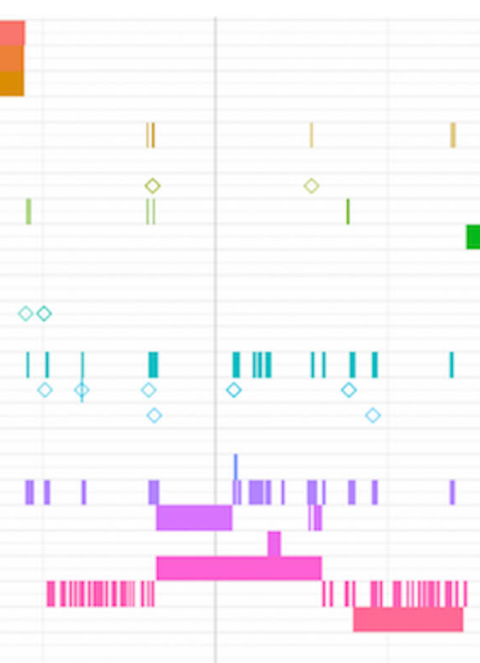

May 01 18:00

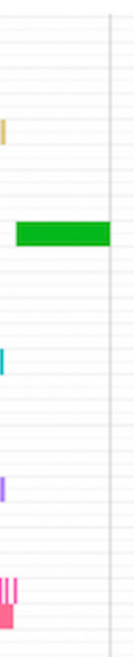

May $0200: 00$

Fig. 7 Overall daily activity analysis of one participant over a 24-h period 


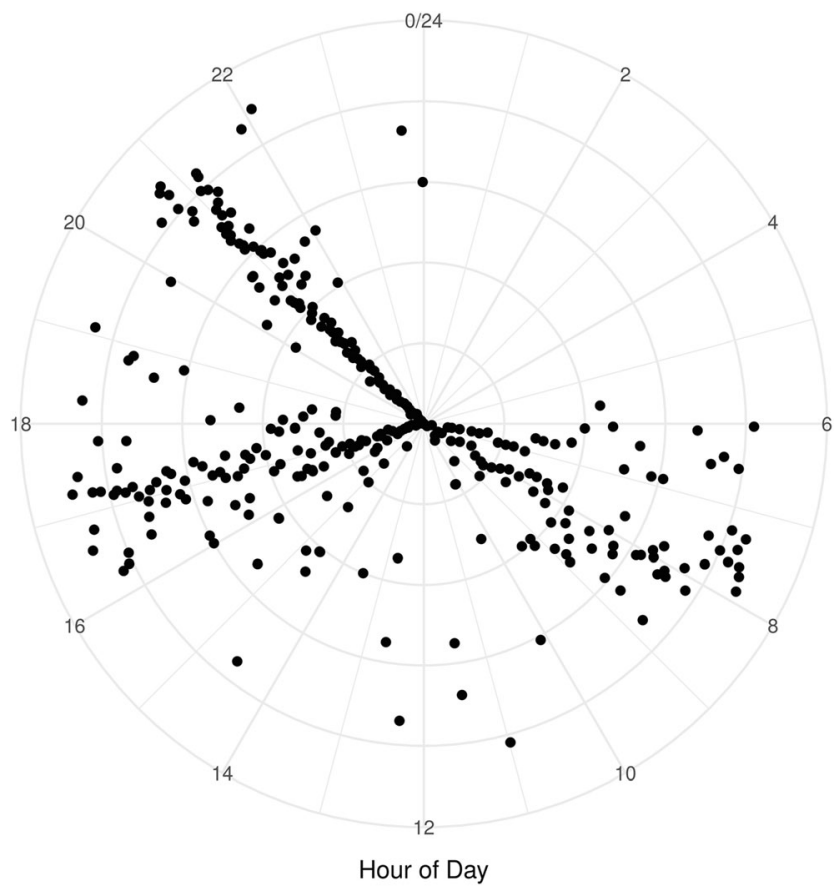

Fig. 8 Specific activity analysis demonstrating medication compliance routines

afternoon. S/he has fairly consistent sleep patterns, going to bed around $9 \mathrm{pm}$ each evening and rising around $7 \mathrm{am}$. By contrast to participant A however, participant B consistently has interruptions in their sleep as noted by the green and yellow colored breaks in the blue colored time-in-bed status during the night. When

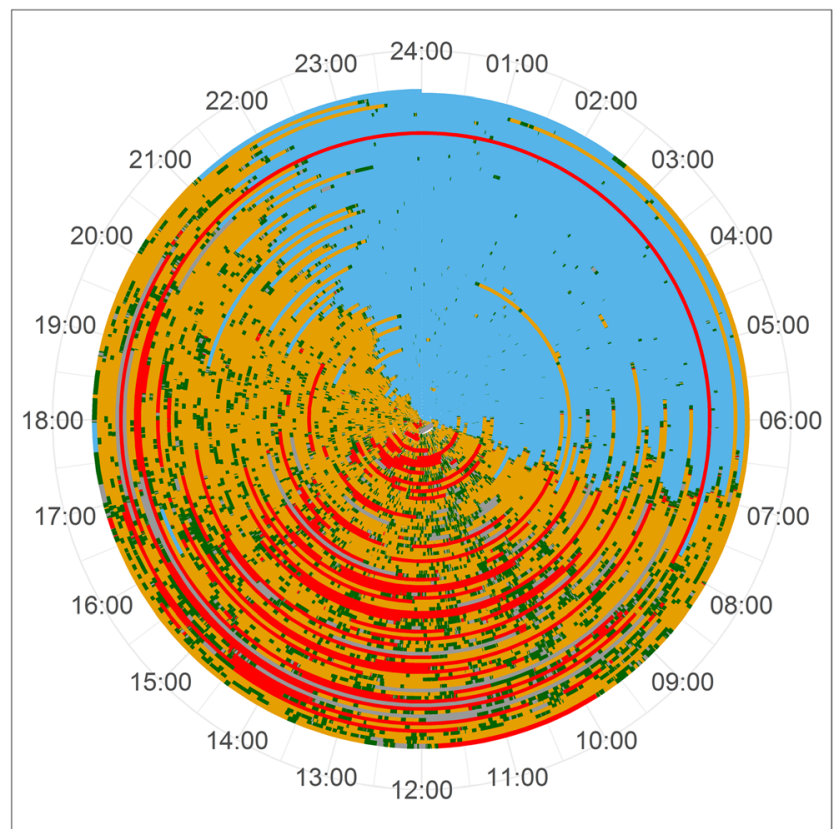

- Active - Sedentary - In-bed - Out-of-home - Unobservable

Fig. 9 Daily participant status for Participant A. The average percentage of daily duration of active is $12 \%$, sedentary $37 \%$, in-bed $36 \%$, out-ofhome $11 \%$, and unobservable $4 \%$

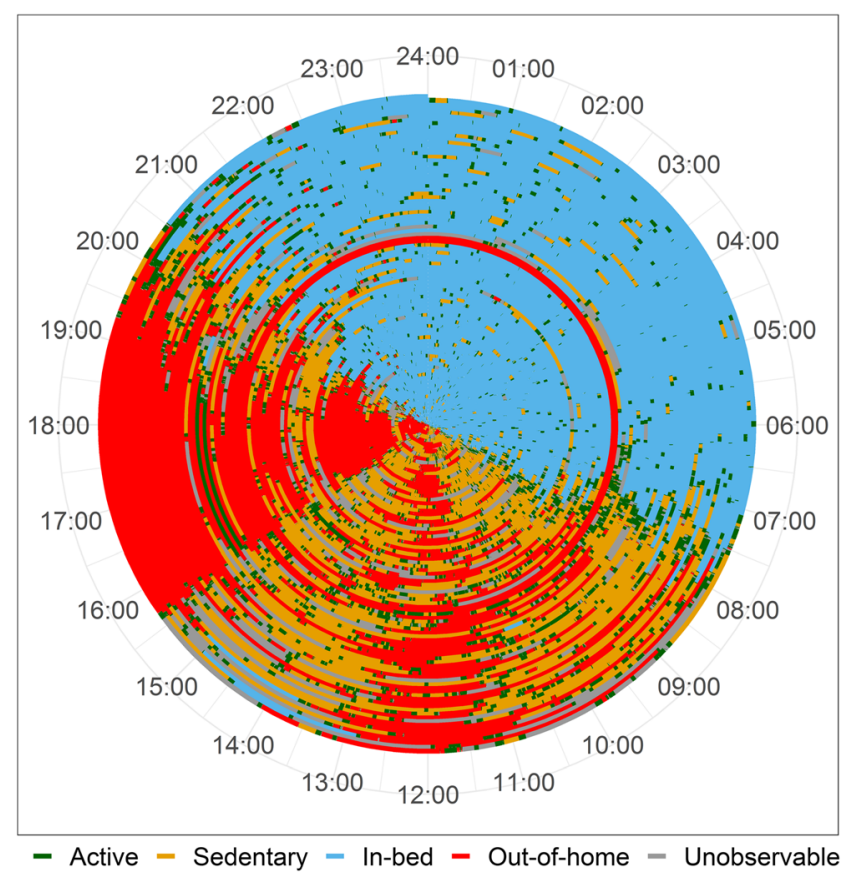

Fig. 10 Daily participant status for Participant B. The average percentage of daily duration of active is $8 \%$, sedentary $20 \%$, in-bed $41 \%$, out-ofhome $25 \%$, and unobservable $6 \%$

examining the medical history of both participants, it is noted that Participant B self-reports a diagnosis of Irritable Bowel Syndrome (IBS), a condition known to impact sleep patterns. Given the importance of consistent sleep for immune, physical and social health in late life, these type of visualizations yield an opportunity to explore the potential impact IBS has on the sleep patterns, and to explore the potential positive benefits of changes in medications or dosing could have on the patient's sleep and quality of life. While beyond the scope of the present IRB, given that participant B initially declined medication for IBS under the auspice that it was not problematic enough to interfere with their daily life, health coaching supported by these types of data-driven outcomes may yield substantive change in outlook and willingness to engage in active treatment.

\subsection{Data analytics}

Ambient sensors create a data-rich environment, but are not without challenges. For example, ambient sensors installed in private homes are relatively inaccessible requiring coordination between the research team and the participant in cases where maintenance is needed. Given the complex nature of participants' lives and varied commitments, it can often take days or weeks to service or replace malfunctioning devices. Since double sensing of every event in the home is cost-prohibitive and may feel unnecessarily intrusive, extracting reliable and 
accurate information requires the ability to adequately compensate for occasionally missing or inaccurate data. To this end, we have developed a number of data imputation tools for dealing with missing or inaccurate data. For example, pressure sensors used to monitor participants sleeping patterns may malfunction, or heavy objects placed on the beds can create inaccurate data that is not representative of the behavior of interest. Accurate information related to understanding sleeping patterns through bed sensors must therefore be supplemented with information from other ambient sensors. Figure 11 shows such an example where the data from a bed pressure sensor is imputed with the information from motion sensors in the network to estimate time in bed.

In addition to the challenges associated with sensor failures, ambient data can also be skewed by the presence of long term visitors who may alter a participant from their normal routine (e.g. eating more meals out) and/or alter patterns of behavior, device usage, and time spent in various activities or areas within their home (e.g. guests often increase the use of guest bathroom spaces within a home). Identification of such time periods is critical for accurate assessment of the participant's health and wellness as these periods may not signal adverse deviations in health, but rather only signal changes in the number/type of residents within a home. Using features from ambient sensor data, we group days into different categories to identify those representative of the participant's normal activities and those that may be skewed by the presence of visitors and/or sensor system related issues. Figure 12 shows a cluster plot of the days for a 9-month period clustered into 3 categories where the $\mathrm{x}$ and $\mathrm{y}$-axis are the two most significant principal components which are linear combinations of the original features [67]. The red cluster shows days that are representative of the participant's normal routine when home alone, the green cluster shows days where the participant had visitors and the blue cluster represents days where there were visitors and one or more sensors malfunctioned.

\section{Supplemental health assessments: A mechanism to elucidate the relationship between home behaviors and health in the long term}

One of the greatest strengths of an ambient sensing system like HomeSense is its potential to contribute to predictive analytics, facilitating our ability to detect subtle signs of an impending adverse health event well before the event unfolds. As we advance risk detection towards earlier time points, cost of intervention and treatment goes down substantially and quality of life improves [68-70]. For example, identifying a cardiac patient at risk for re-hospitalization prior to a hospitalization event offers potential for thousands of dollars in health care savings, especially where low-cost interventions such as passive weight monitoring and adjustment in diuretic medications can be life altering. Currently, screening for a variety of conditions like depression and cognitive impairment routinely require both costly in-person assessment and access to providers/care [71]; factors which in turn often delay the onset of treatment and contribute to rising costs. Additionally, these screenings provide a measurement of the condition only at a single point in time and fall short of monitoring its continuous progression [72]. Ambient sensing platforms continuously monitor and identify home-based behaviors that may signal onset/start of these conditions without the need for regular screening via formal administration of standardized survey tools - enhancing patient's overall quality of life as care and outcomes are improved, without disrupting their day-to-day lives [73].

As a foundation in elucidating these relationships, all participants in the HomeSense project participate in both a Comprehensive Health Assessment (CHA) at program start, and an on-going Bi-weekly Health Assessment (BWA). CHAs are administered in person and utilize standardized surveys in a variety of domains to collect information on participants' demographic backgrounds, social support, functional status, falls risk, alcohol and substance use, nutritional habits, medication adherence, mental health, cognitive

Time in Bed Estimation Comparison

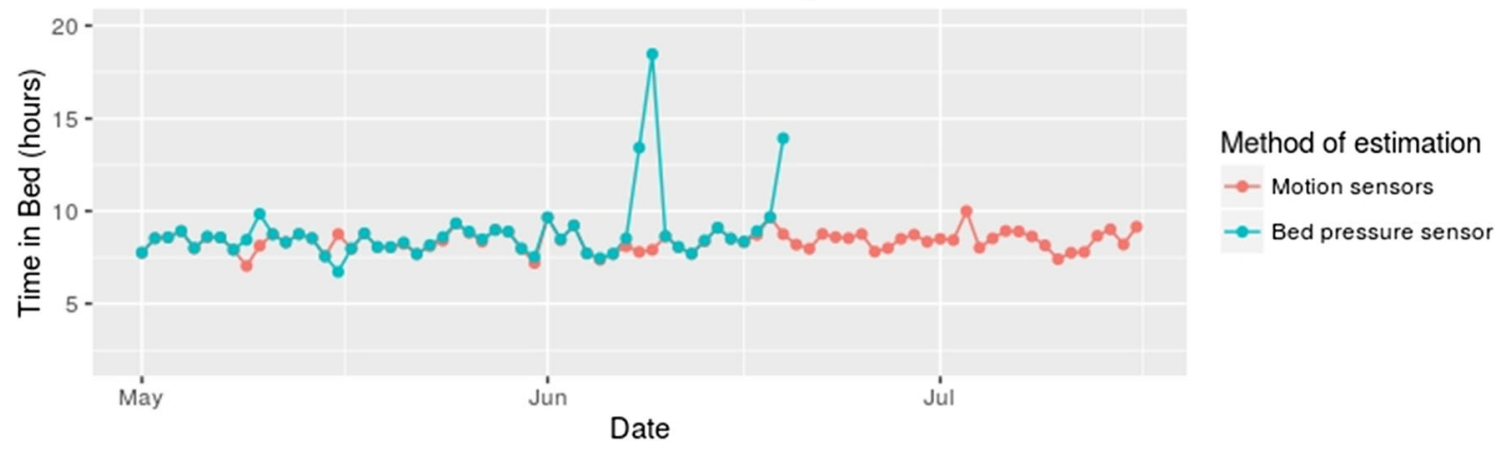

Fig. 11 Example of data imputation to replace missing or inaccurate data 
Fig. 12 Descriptive data models for classification of normal vs abnormal days

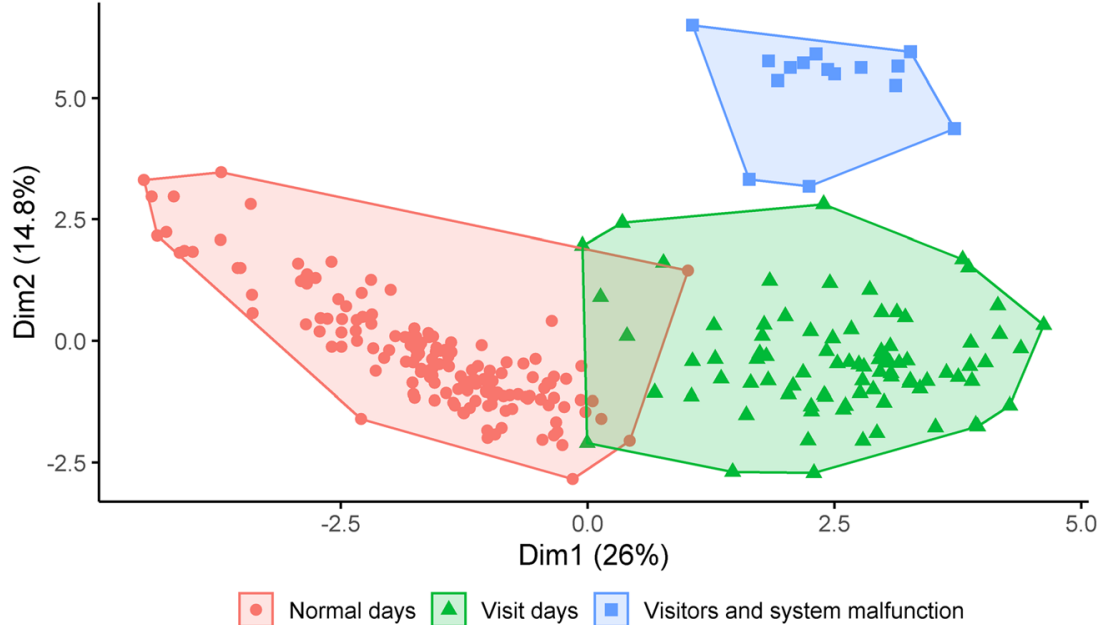

function, and sleep quality. Further details regarding CHA instruments are shown in Table 4. To reduce participant burden, BWA's utilize a split ballot design [74] to collect information by phone in a variety of domains such as mental and social health, loneliness, pain and sleep quality on an ongoing basis. Utilizing the 'split ballot' process, a small fixed set of primary questions is asked every 2 weeks. Additionally, a standardized, rotating 'ballot' of questions is asked such that data is collected for each question 'set' bi-monthly. This process facilitates the on-going understanding of a broad range of health outcomes over time, while limiting total telephone interview time to no more than 30 minutes Details of the

Table 4 List of CHA Instruments

\begin{tabular}{|c|c|c|}
\hline Type & $\begin{array}{l}\# \text { of } \\
\text { Items }\end{array}$ & Short Description \\
\hline Demographic questions & 14 & $\begin{array}{l}\text { Assessing age, gender, education, employment, relationship status, residence, primary care } \\
\text { status, chronic conditions, family history, self-reported health, medications, and commu- } \\
\text { nity activity participation. }\end{array}$ \\
\hline $\begin{array}{l}\text { DUKE-UNC Functional Social Support } \\
\text { Questionnaire (FSSQ) [54] }\end{array}$ & 8 & $\begin{array}{l}\text { Measure of functional support. Higher scores reflect higher perceived support. Cronbach's } \alpha \\
.85 \text {. }\end{array}$ \\
\hline RAND Social Health Battery [75] & 11 & $\begin{array}{l}\text { Measure of social health and engagement where higher scores reflect higher engagement. } \\
\text { Cronbach's } \alpha .84 \text {. }\end{array}$ \\
\hline ECOG Performance Status [57] & 1 & Measure of ADL limitation where a higher score indicated increased limits in ADL ability. \\
\hline Desmond Fall Risk Questionnaire [58] & 15 & $\begin{array}{l}\text { Assessment of falls risk where positive answer to } 3 \text { or more items indicates potential risk of } \\
\text { falling. }\end{array}$ \\
\hline $\begin{array}{l}\text { Alcohol Use Disorders Identification Test } \\
\quad(\text { Audit-C) [59] }\end{array}$ & 3 & $\begin{array}{l}\text { Assessment of hazardous drinking and alcohol consumption. Scored on a scale of } 0 \text { to } 12 \text { with } \\
3 \text { or more indicating risk for women; } 4 \text { or more indicating risk for men. }\end{array}$ \\
\hline $\begin{array}{l}\text { Alcohol, Smoking and Substance Involvement } \\
\text { Screening Test (ASSIST) [76] }\end{array}$ & 2 & $\begin{array}{l}\text { Measure of lifetime and recent tobacco use. Average test-retest reliability coefficients } \\
\text { (kappas) had a high of } .90 .\end{array}$ \\
\hline Nutrition Checklist [60] & 9 & $\begin{array}{l}\text { Measure of risk for poor nutritional status; scores of } 3 \text { to } 5 \text { indicate moderate nutritional risk, } 6 \\
\text { or more high nutritional risk. Sensitivity } .72 \text {, specificity } .94 \text {. }\end{array}$ \\
\hline $\begin{array}{l}\text { Simplified Medication Adherence Questionnaire } \\
\quad(S M A Q)[77]\end{array}$ & 4 & $\begin{array}{l}\text { Measure of medication adherence where higher scores indicate lower medication adherence. } \\
\text { Cronbach's } \alpha .85 \text {. }\end{array}$ \\
\hline Mental Health Inventory (MHI-5) [53] & 5 & Assessment of depression and anxiety with a cut score of 76. Cronbach's $\alpha .84$. \\
\hline Mini Mental State Exam (MMSE) [78] & 12 & $\begin{array}{l}\text { Measure of cognitive impairment where lower scores indicate greater likelihood of cognitive } \\
\text { impairment. Cronbach's } \alpha .85 \text {. }\end{array}$ \\
\hline $\begin{array}{l}\text { Cognitive and Affective Mindfulness Scale- } \\
\text { Revised (CAMS-R) [79] }\end{array}$ & 12 & $\begin{array}{l}\text { Assessment of mindfulness where higher scores indicate higher mindfulness. Cronbach's } \alpha \\
.81 \text {. }\end{array}$ \\
\hline Pittsburgh Sleep Quality Index (PSQI) [55] & 9 & $\begin{array}{l}\text { Measure of sleep quality and sleep disturbances where a score of } 5 \text { or greater is indicative of } \\
\text { poorer sleep quality. Sensitivity of } 98.7 \text { and specificity of } 84.4 \text { as a marker for sleep } \\
\text { disturbances in insomnia patients versus controls. }\end{array}$ \\
\hline Timed “Up \& Go” test $[80]$ & 1 & $\begin{array}{l}\text { Timed measure of physical mobility. Scores greater than } 13.5 \mathrm{~s} \text { indicate mobility challenges. } \\
\text { Sensitivity } 0.32 \text { and specificity } 0.73 \text {. }\end{array}$ \\
\hline
\end{tabular}


BWA and domains assessed with each of the 4 administered 'ballots' are shown in Table 5. In both the CHA and the BWA, instruments were selected on the basis of length (prioritizing short, high-salience instruments), historical reliability and validity of the tool, acceptance/adoption by members of the health community (priority was given to tools used in existing national studies), and prior use with older-adult populations.

Collection and integration of these data points facilitate complex analytics that allow us to examine long term health and behavior trends that may signal system deficits, changes in habits, and risk or resilience over time. For example, data collected from tools such as the MHI-5 and MMSE can allow us to monitor changes in mental and cognitive health over time and allow us to examine corollary changes in homebased behaviors such as sleep, nutrition and bathing habits. Additionally, when integrated with health outcomes, the volume and capacity of data produced by HomeSense facilitate our ability to explore and identify novel behavioral risk factors that may signal change 'up stream', to do profile-based algorithm development, to improve 'reasoning' in notification generation, and to do health outcomes and cost-benefit analysis. Further, when combined with electronic medical records data including health outcomes, health service utilization and health costs, on-going monitoring offers significant potential to inform understanding of the relationship between homebased behaviors and risk for adverse events.

\subsection{Exploring trends in bi-weekly health assessments}

Bi-weekly assessments are an important source of information in tracking and understanding changes in the participants' health and wellness. They serve as means to monitor life events such as holidays, vacations and visitors. We have developed a bi-weekly assessment visualization tool which allows us to explore trends over time for standardized health assessments for each participant. Figure 13 below shows a participant's response to the RAND Social Health Battery score over the course of 28 months. Scores range from 27 to 47 , with higher scores representing higher levels of social support. Available comments from the participant associated with each score are listed under the plot. With scores represented on the $\mathrm{Y}$ axis and dates on the $\mathrm{X}$ axis, these tools allow our research team to identify changes and/or trends over time, and to explore how ambient sensor data can be used to confirm, identify and/or even predict such trends as we progress. In this example, the participant's social health score varies by nearly 10 points between 7/26/16 and 10/13/16. Given recent research on the costs and health impacts of loneliness [87], changes in home-based behaviors such as sleep/wake time, sedentary behavior and time outside home can be examined over the same timeframes to identify changes that may signal onset or worsening social health can be explored via the sensor data.

\section{Discussion and future research}

As the population of older adults continues to soar to record levels and with it the number of persons living with costs and burden of chronic disease, new strategies are needed to enhance health care quality and health outcomes in communitybased environments [88]. Older adults have expressed a strong desire to age in place [16], but absent appropriate monitoring and supports, they can suffer increased risk for accident and injury, heightened comorbidity and even death [23, 24]. Tools such as the ambient sensing platform described in this paper offer the potential to monitor older adults within their own homes, facilitating supportive environments that bolster the healthy, safe and independent aging plan preferred by older

Table 5 List of BWA Instruments

\begin{tabular}{|c|c|c|c|}
\hline Type & $\begin{array}{l}\text { \# of } \\
\text { Items }\end{array}$ & Short Description & $\begin{array}{l}\text { Administration } \\
\text { Schedule }\end{array}$ \\
\hline $\begin{array}{l}\text { Self-Reported Activity and } \\
\text { Health Status }\end{array}$ & 10 & $\begin{array}{l}\text { Identifying changes in self-reported health, health-service utilization, changes in } \\
\text { co-morbid conditions or medications, activity participation, travel plans and } \\
\text { company at home }\end{array}$ & Ballots $1-4$ /Weeks $2-8$ \\
\hline $\begin{array}{l}\text { Patient Health Questionnaire } \\
\quad(P H Q-2)[81]\end{array}$ & 2 & $\begin{array}{l}\text { Screening for potential depression symptomology. Sensitivity of .86 and specificity } \\
\text { of } .78 \text { for diagnosing major depression }\end{array}$ & Ballots 1-4/Weeks 2-8 \\
\hline $\begin{array}{l}\text { Physical Activity Scale (PASE) } \\
\text { [82] }\end{array}$ & 21 & $\begin{array}{l}\text { Measure of physical activity and mobility where higher scores indicate greater } \\
\text { mobility and activity levels }\end{array}$ & Ballot 4/Week 8 \\
\hline $\begin{array}{l}\text { Loneliness (UCLA Loneliness } \\
\quad \text { Scale) [83] }\end{array}$ & 20 & Assessment of loneliness where higher scores indicate greater loneliness & Ballot 2/Week 4 \\
\hline Falls Efficacy Scale [84] & 10 & Measure to assess fear of falling, scores over 70 indicate a fear of falling & Ballot 4/Week 8 \\
\hline Geriatric Pain Measure [85] & 24 & $\begin{array}{l}\text { Assessment of pain in older adults, scores range from } 0 \text { to } 42 \text { with higher scores } \\
\text { indicating more pain. }\end{array}$ & Ballot 1/Week 2 \\
\hline $\begin{array}{l}\text { Telephone Interview for } \\
\quad \text { Cognitive Status (TICS) [86] }\end{array}$ & 11 & $\begin{array}{l}\text { Phone-based assessment for cognitive status. Performance was significantly } \\
\text { correlated with MMSE score }(\mathrm{r}=0.86, p<0.001)\end{array}$ & Ballot 3/Week 6 \\
\hline
\end{tabular}




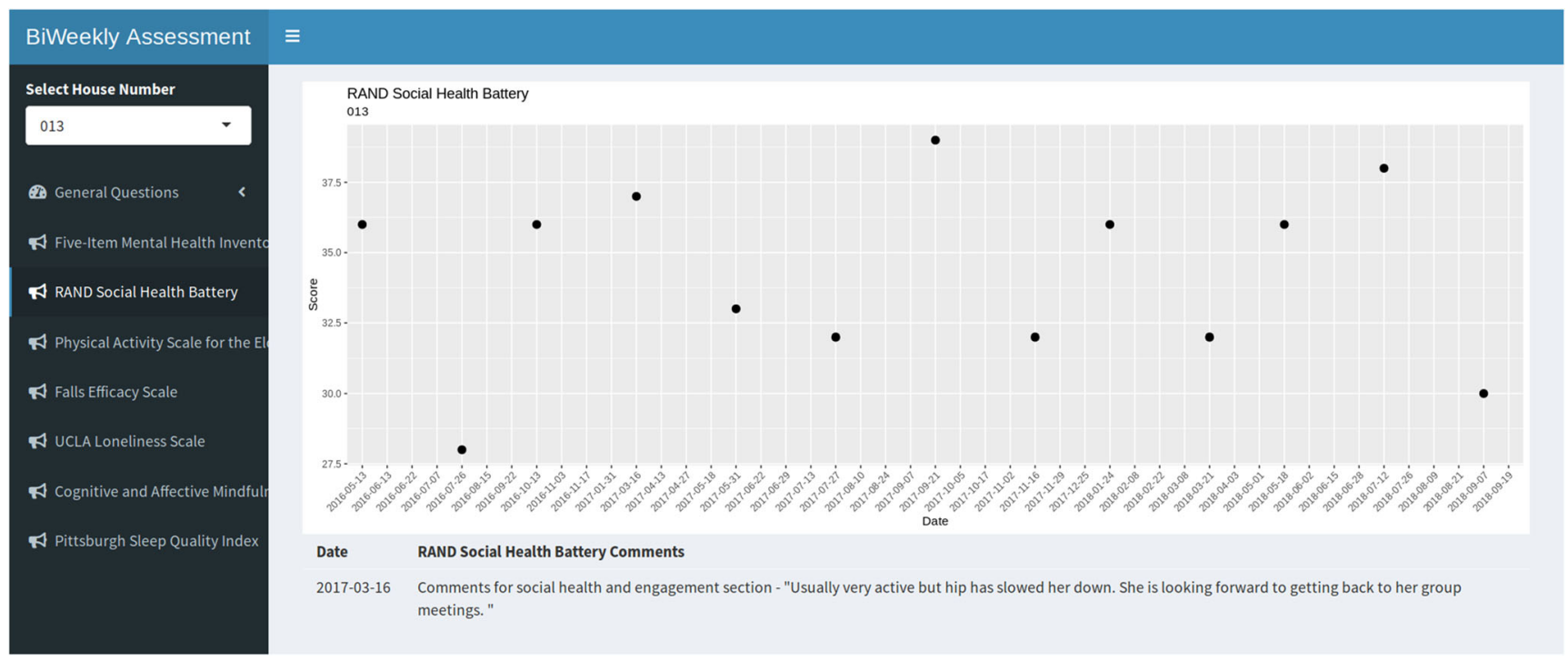

Fig. 13 Bi-weekly Health Assessment analysis showing participants response to RAND Social Health Battery over 28 months

cohorts. The ability HomeSense provides to monitor/observe older adults in their own environments can help to prioritize care to those in need of touch points - in effect, extending the health care workforce which will become increasingly important as the caregiver support ratio declines [5] and institutional systems struggle to meet increasing demand [4]. Additionally, when integrated with health outcomes and service utilization data, home-based behavior information collected from ambient home sensing tools like HomeSense has the power to unlock subtle, 'upstream' indicators that may signal the advent of costly adverse health events, well before the event unfolds [28].

As Anya \& Tawfik [26] note, design of technologies for the elderly should, "be driven by an understanding of the actual need for the technology, ease of learning to use the technology, the elderly person's cognitive and perceptual abilities, as well as other sociopsychological factors such as preferences, attitudes, and beliefs". At its core, HomeSense was built utilizing a community-based participatory research (CBPR) approach [46] to engage key stakeholders in its development, and each of the four phases of its evolution have been directly informed by, and built in conjunction with stakeholders such as older adults, family members (i.e. adult children and spouses), providers (i.e. primary and specialty care physicians, home health service agencies), informal caregivers, members of senior advocacy groups, and payers with a vested interest in ensuring older adults live well, safely in their homes. This has helped ensure that HomeSense is responsive to its user needs, preferences and abilities, and has translated in a desire for users to keep the system well beyond 6-month program completion benchmarks agreed to at the program start. As the program continues to grow and expand, researchers are mindful that technology must continue to be respectful of these needs and preferences. Inherent risks around issues such as privacy, data security and diminishing human interaction are present in remote sensing tools such as HomeSense and to offset the cost, the returns for end users must be both real and realized.

A variety of methods have been suggested for elucidating the relationship between home-based behaviors and health, these include use of computer vision and pattern recognition [89], application of fuzzy logic [90] and machine learning [91], use of Artificial Neural Networks [92], Bayesian networks [93], Poincaré Plots [33] Markov Models [94], Ontology-Based Context Modeling [95] and application of LeZi algorithms [96]. HomeSense's data model associating meta-information with the data collected from the sensors is designed to facilitate such machine learning and data mining techniques. We are currently exploring ways to improve prediction and reasoning about health and behavior to inform adaptation of home environments, support structures and/or interventions and preventions as relationships between behaviors and outcomes become better understood.

Creating responsive, adaptive and beneficial home environments to facilitate aging in place requires complementing sensing with mechanisms to add context to observed sensory information. For example, sensory information can determine if a resident does not get out of bed past their usual time but falls short of explaining the context for this behavior. Targeted interactions with the resident to elicit context for critical sensory observations is a potential solution to bridge this gap [97]. We are currently exploring integration of AVATARs and digital humans such as those offered by CREATEAbility Concepts (www.createabilityinc.com) and FaceMe (www.FaceMe.com) into HomeSense to support bidirectional communication with residents and to further facilitate reasoning and understanding of the role of context in health and behavior at home. 
Acknowledgements The authors wish to thank the participants who allowed HomeSense into their daily lives and The Villages citizenry and leadership for supporting our study within their community. We also wish to thank CREATE Health's current and former team members Luigi Guillermo Pugliese, Evan Zapf, Efe Yetisener, Julie Hammett, Erica Sappington and Caron Watkins who have helped make this project a success.

Funding information There is no funding source.

\section{Compliance with ethical standards}

Conflict of interest The authors declare that they have no conflict of interest.

Ethical approval This article does not contain any studies with human participants or animals performed by any of the authors.

Informed consent Informed consent was obtained from all individual participants included in the study.

Open Access This article is licensed under a Creative Commons Attribution 4.0 International License, which permits use, sharing, adaptation, distribution and reproduction in any medium or format, as long as you give appropriate credit to the original author(s) and the source, provide a link to the Creative Commons licence, and indicate if changes were made. The images or other third party material in this article are included in the article's Creative Commons licence, unless indicated otherwise in a credit line to the material. If material is not included in the article's Creative Commons licence and your intended use is not permitted by statutory regulation or exceeds the permitted use, you will need to obtain permission directly from the copyright holder. To view a copy of this licence, visit http://creativecommons.org/licenses/by/4.0/.

\section{References}

1. US Census Bureau. 2011-2015 American community survey 5year estimates. Population 65 years and over in the United States. 2017.

2. World Health Organization. Ageing and health in global strategy and action plan on ageing and health. Geneva: World Health Organization; 2017. Available from: https:/www.who.int/ageing/ WHO-GSAP-2017.pdf?ua=1

3. United Nations, Department of Economic and Social Affairs, Population Division (2015). World Population Ageing (ST/ESA/ SER.A/390). Available from: https://www.un.org/en/development/ desa/population/publications/pdf/ageing/WPA2015_Report.pdf

4. Vincent G, Celkoff V. The next four decades: the older population in the United States 2010 to 2050. Washington, D.C.: U.S. Department of Commerce, Economics and Statistics Administration, U.S. Census Bureau; 2010. Available from: https://www.census.gov/library/ publications/2010/demo/p25-1138.html

5. Redfoot D, Feinberg L, Houser A. The aging of the baby boom and the growing care gap: a look at future declines in the availability of family caregivers. Washington, DC: AARP Public Policy Institute; 2013. Available from: https://www.aarp.org/content/dam/aarp/ research/public policy institute/ltc/2013/baby-boom-and-thegrowing-care-gap-insight-AARP-ppi-ltc.pdf

6. Pearson WS, Bhat-Schelbert K, Probst JC. Multiple chronic conditions and the aging of America: challenge for primary care physicians. J Prim Care Community Health. 2012;3:51-6.
7. Centers for Disease Control and Prevention. The state of aging and health in America 2013. Atlanta: Centers for Disease Control and Prevention, US Department of Health and Human Services; 2013.

8. Buttorff C, Ruder T, Bauman M. Multiple chronic conditions in the United States. Santa Monica: RAND; 2017. p. 2017.

9. Hung WW, Ross JS, Boockvar KS, Siu AL. Association of chronic diseases and impairments with disability in older adults: a decade of change? Med Care. 2012;50(6):501-7. https://doi.org/10.1097/ MLR.0b013e318245a0e 0.

10. Meek KP, Bergeron CD, Towne SD, Ahn S, Ory MG, Smith ML. Restricted social engagement among adults living with chronic conditions. Int J Environ Res Public Health. 2018;15(1):158. https:// doi.org/10.3390/ijerph15010158.

11. Dunlop D, Lyons J, Manheim L, Song J, Chang R. Arthritis and heart disease as risk factors for major depression: the role of functional limitation. Med Care. 2004;42(6):502-11.

12. Luppa M, Luck T, Weyerer S, König H-H, Brähler E, Riedel-Heller SG. Prediction of institutionalization in the elderly. A systematic review. Age Ageing. 2009;39(1):31-8. https://doi.org/10.1093/ ageing/afp202.

13. "Health Affairs: Health spending projections through 2027," Health Affairs Blog, February 22, 2019. https://doi.org/10.1377/ hblog20190221.997607.

14. Hoffman C, Rice D, Sung H. Persons with chronic conditions: their prevalence and costs. J Am Med Assoc. 2012;276(18):1473-9.

15. Porter $\mathrm{M}$. What is value in health care? N Engl J Med. 2010;363(26):2477-81.

16. Mather M, Jacobssen L, Pollard KM. Aging in the United States. Popul Bull. 2015;2(70):2-17.

17. Centers for Disease Control and Prevention. Healthy places terminology. 2017. Available from: https://www.cdc.gov/healthyplaces/ terminology.htm

18. Graybill E, McMeekin P, Wildman J. Can aging in place be cost effective? A systematic review. PLoS One. 2014;9(7):e102705.

19. Wiles J, Leibing A, Guberman N, Reeve J, Allen R. The meaning of "aging in place" to older people. The Gerontologist. 2012;52(3): 357-66.

20. Grimmer K, Kay D, Foot J, Pastakia K. Consumer views about aging in place. Clin Interv Aging. 2015;10:1803-11.

21. Carver L, Beamish R, Phillips S, Villeneuve M. A scoping review: social participation as a cornerstone of successful aging in place among rural older adults. Geriatrics. 2018;3(4):75.

22. Kaplan D, Andersen T, Lehning A, Perry T. Aging in place vs. relocation for older adults with a neurocognitive disorder: applications of Wiseman's behavioral model. J Gerontol Soc Work. 2015;58(5):521-38.

23. Feng M, Murphy M, Mlinac M. Independent living capacity evaluation in home-based primary care: considerations and outcomes of a quality improvement project. Clin Gerontol. 2017;40(1):51-62.

24. Mills W, Regev T, Kunik M, Wilson N, Moye J, McCullough L, Naik A. Making and executing decisions for safe and independent living (MED-SAIL): development and validation of a brief screening tool. Am J Geriatr Psychiatr. 2014;22(3):285-93.

25. Augusto J, Callaghan V, Cook D, Karneas A, Satoh I. Intelligent environments: a manifesto. Human-Centric Comput Inf Sci. 2013;3(12):1-18.

26. Anya $\mathrm{O}$, Tawfik $\mathrm{H}$. Leveraging big data analytics for personalized elderly care: opportunities and challenges. Appl Comput Med Health. 2016:99-124.

27. Bates D, Saria S, Ohno-Machado L, Shah A, Escobar G. Big data in health care: using analytics to identify and manage high-risk and high-cost patients. Predictive Anal. 2014;33(7):1123-31.

28. Uddin M, Khaksar W, Torrensen J. Ambient sensors for elderly care and independent living: a survey. Sensors. 2018;18:2027-58.

29. Lotfi A, Langensiepen C, Mahmound S, Akhlaghinia M. Smart homes for the elderly dementia suffers: identification and prediction 
of abnormal behavior. J Ambient Intell Humaniz Comput. 2012;3(3):205-18.

30. Majumder S, Aghayi E, Noferesti M, Memarzadeh-Tehran H, Mondal T, Pang Z, Deen J. Smart homes for elderly healthcarerecent advances and research challenges. Sensors. 2017;17:2496. https://doi.org/10.3390/s17112496.

31. Riboni D, Bettini C, Civitarese G, Janjua Z, Helaoui R. SmartFABER: recognizing fine-grained abnormal behaviors for early detection of mild cognitive impairment. Artif Intell Med. 2016;67:57-74.

32. Sanchez V, Pfeiffer C, Skeie N. A review of smart house analysis methods for assisting older people living alone. Sens Actuator Netw. 2017;6(11):1-38.

33. Urwyler P, Stucki R, Rampa L, Muri R, Mosimann U, Nef T. Cognitive impairment categorized in community-dwelling older adults with and without dementia using in-home sensors that recognize activities of daily living. Sci Rep. 2017;7:1-9.

34. Petersen J, Austin D, Kaye JA, Pavel M, Hayes TL. Unobtrusive inhome detection of time spent out-of-home with applications to loneliness and physical activity. IEEE J Biomed Health Inform. 2013;18(5):1590-6.

35. Rao S, Cook D. Predicting inhabitant actions using action and task models with application to smart homes. Int $\mathrm{J}$ Artif Intell Tools. 2004;13(1):81-100

36. Abowd G, Bobick A, Essa I, Mynatt E, Rogers W. The aware home: a living laboratory for technologies for successful aging. In: Proceedings of the AAAI-02 workshop "automation as caregiver. 2002. Available from: https://www.aaai.org/Papers/Workshops/ 2002/WS-02-02/WS02-02-001.pdf

37. Helal S, Mann W, El-Zabadani H, King J, Kaddoura Y, Jansen E. The gator tech smart house: a programmable pervasive space. Computer. 2005;38:50-60.

38. Agoulmine N, Deen MJ, Lee J, Meyyappan M. U-health smart home. IEEE Nanotechnol Mag. 2011;5(3):6-11.

39. Deen MJ. Information and communications technologies for elderly ubiquitous healthcare in a smart home. Pers Ubiquit Comput. 2015;19(3):573-99.

40. Kim J, Choi H, Wang H, Agoulmine N, Deerv MJ, Hong JW, editors. POSTECH's U-Health Smart Home for elderly monitoring and support. In: 2010 IEEE international symposium on "A world of wireless, mobile and multimedia networks" (WoWMoM); 2010 14-17 June 2010

41. Majumder S, Mondal T, Deen MJ. Wearable sensors for remote health monitoring. Sensors (Basel, Switzerland). 2017;17(1):130.

42. Intille S, Larson K, Tapia E, Beaudin J, Kaushik P, Nawyn J, Rockinson R. Using a live-in laboratory for ubiquitous computing research. In: Universal access in human-computer interaction ambient interaction, 3968 LNCS; 2006. pp. 349-365.

43. Rantz M, Skubic M, Miller S. Using sensor technology to augment traditional health-care. In: Conference proceedings: annual international conference of the IEEE engineering in medicine and biology society IEEE engineering in medicine and biology society conference. 2009. pp. 6159-6162. https://doi.org/10.1109/IEMBS.2009. 5334587.

44. Williams J, Cook D. Forecasting behavior in smart homes based on sleep and wake patterns. Technol Health Care. 2017;25(1):89-110.

45. Jacobs PG, Kaye JA. Ubiquitous real-world sensing and audiologybased health informatics. J Am Acad Audiol. 2015;26:777-83.

46. Holkup P, Tripp-Reimer T, Salois E, Weinert C. Community-based participatory research an approach to intervention research. Ann Nurs Sci. 2004;27(3):162-75.

47. Bernard S. Risk adjustment documentation \& coding. Chicago: American Medical Association; 2018.

48. Bach L, Mortimer J, VandeWeerd C, Corvin J. The association of physical and mental health with sexual activity in older adults in
The Villages, Florida. J Sex Med. 2013;10(11):2671-8. https://doi. org/10.1111/jsm.12308.

49. Fishleder S, Shonfeld L, Corvin J, Tyler S, Vandeweerd C. Drinking behavior among older adults in a planned retirement community: results from The Villages survey. Int J Psychiatry. 2016;31(5):53643

50. Tyler S, Corvin J, McNab P, Fishleder S, Blunt H, VandeWeerd, C. "You can't get a side of willpower:" supports and barriers to healthy eating in The Villages. J Nutr Gerontol Geriatr. 2014;33(2):1-18. https://doi.org/10.1080/21551197.2014.907760.

51. Folstein M, Folstein S, McHugh P. 'Mini-mental state': a practical method for grading the cognitive state of patients for the clinician. J Psychiatr Res. 1975;12:189-98.

52. Walsh SP, Raman R, Jones KB, Aisen PS, Alzheimer's Disease Cooperative Study Group. ADCS prevention instrument project: the mail-in cognitive function screening instrument (MCFSI). Alzheimer Dis Assoc Disord. 2006;20:S170-8.

53. Berwick DM, Murphy JM, Goldman PA, Ware JE, Barsky AJ, Weinstein MC. Performance of a five-item mental health screening test. Med Care. 1991;29(2):169-76.

54. Broadhead WE, Gehlbach SH, DeGruy FV, Kaplan BH. The DukeUNC functional social support questionnaire: measurement of social support in family medicine patients. Med Care. 1988;26(7):709-23.

55. Backhaus J, Junghanns K, Broocks A, Riemann D, Hohagen F. Test-retest reliability and validity of the Pittsburgh sleep quality index in primary insomnia. J Psychosom Res. 2002;53(3):737-40.

56. Podsiadlo D, Richardson S. The timed "up \& go": a test of basic functional mobility for frail elderly persons. J Am Geriatr Soc. 1991;39(2):142-8.

57. Zubrod CG, Schneiderman M, Frei III E, Brindley C, Gold GL, Shnider B, ... Colsky J. Appraisal of methods for the study of chemotherapy of cancer in man: comparative therapeutic trial of nitrogen mustard and triethylene thiophosphoramide. J Chronic Dis, 1960;11(1):7-33.

58. Desmond A. Fall risk questionnaire and physician's guide - part V. 2011. Available from: https://hearinghealthmatters.org/ dizzinessdepot/2011/fall-risk-questionnaire-and-physicians-guidepart-v/

59. Bush K, Kivlahan DR, McDonell MB, Fihn SD, Bradley KA. The AUDIT alcohol consumption questions (AUDIT-C): an effective brief screening test for problem drinking. Arch Intern Med. 1998;158(16):1789-95.

60. Posner BM, Jette AM, Smith KW, Miller DR. Nutrition and health risks in the elderly: the nutrition screening initiative. Am J Public Health. 1993;83(7):972-8.

61. Strine TW, Chapman DP. Associations of frequent sleep insufficiency with health-related quality of life and health behaviors. Sleep Med. 2005;6(1):23-7. https://doi.org/10.1016/j.sleep.2004.06.003.

62. US Department of Health and Human Services. Bone health and osteoporosis: a report of the surgeon general. Rockville: US Department of Health and Human Services, Office of the Surgeon General; 2004. p. 87.

63. Min JY, Min KB. Outdoor artificial nighttime light and use of hypnotic medications in older adults: a population-based cohort study. $\mathrm{J}$ Clin Sleep Med. 2018;14(11):1903-10.

64. Byrne MD, Jordan TR, Welle T. Comparison of manual versus automated data collection method for an evidence-based nursing practice study. Appl Clin Inform. 2013;4(1):61-74. https://doi. org/10.4338/ACI-2012-09-RA-0037.

65. Wang Y, Yalcin A, VandeWeerd C. Health and wellness monitoring using ambient sensor networks. J Ambient Intell Smart Environ. 2020;12(2):139-151.

66. Kroenke K, Spitzer RL, Williams JB. The patient health questionnaire-2: validity of a two-item depression screener. Med Care. 2003: 1284-92. 
67. Dunteman GH. Principal components analysis (no. 69). Thousand Oaks: Sage; 1989.

68. Borson S, Frank L, Bayley PJ, Boustani M, Dean M, Lin PJ, et al. Improving dementia care: the role of screening and detection of cognitive impairment. Alzheimers Dement. 2013;9(2):151-9.

69. Egede LE. Failure to recognize depression in primary care: issues and challenges. J Gen Intern Med. 2007;22(5):701-3.

70. Ahn S, Smith M, Altpeter M, Post L, Ory M. Healthcare cost savings estimator tool for chronic disease self-management program: a new tool for program administrators and decision makers. Front Public Health. 2015;3:42. https://doi.org/10.3389/fpubh.2015. 00042.

71. Hunter W, Zhang C, Hesson A, Davis K, Kirby C, Williamson L, Barnett J, Ubel P. What strategies do physicians and patients discuss to reduce out-of-pocket costs?: analysis of cost-saving strategies in 1,755 outpatient clinic visits. Med Decis Mak. 2017;36(7):900-10.

72. Path-Theta Collaboration. Optimizing chronic disease management mega-analysis: an economic evaluation. Ontario Health Technol Assess Ser. 2013;13(13):1-148.

73. Kaye JA, Maxwell SA, Mattek N, Hayes TL, Dodge H, Pavel M, Zitzelberger TA. Intelligent systems for assessing aging changes: home-based, unobtrusive, and continuous assessment of aging. J Gerontol B Psychol Sci Soc Sci. 2011;66(Suppl. 1):180-90.

74. Revilla M, Saris W. The split-ballot multitrait-multimethod approach: implementation and problems. Struct Equ Model Multidiscip J. 2013;20:27-46. https://doi.org/10.1080/10705511. 2013.742379.

75. McDowell I. Measuring health: a guide to rating scales and questionnaires. New York: Oxford University Press; 2006.

76. World Health Organization ASSIST Working Group. The alcohol, smoking and substance involvement screening test (ASSIST): development. Geneva: World Health Organization; 2002.

77. Ortega F, Sánchez Plumed J, Pérez V, Pereira Palomo P, Muñoz Cepeda MA, Lorenzo Aguiar D. Validation on the simplified medication adherence questionnaire (SMAQ) in renal transplant patients on tacrolimus. Nefrologia. 2011;31:690-6. https://doi.org/ 10.3265/Nefrologia.pre2011.Aug.10973.

78. Tombaugh TN, McIntyre NJ. The mini-mental state examination: a comprehensive review. J Am Geriatr Soc. 1992;40(9):922-35.

79. Park T, Reilly-Spong M, Gross CR. Mindfulness: a systematic review of instruments to measure an emergent patient-reported outcome (PRO). Qual Life Res. 2013;22(10):2639-59. https://doi.org/ 10.1007/s11136-013-0395-8.

80. Barry E, Galvin R, Keogh C, Horgan F, Fahey T. Is the timed up and go test a useful predictor of risk of falls in community dwelling older adults: a systematic review and meta-analysis. BMC Geriatr. 2014;14:14. https://doi.org/10.1186/1471-2318-14-14.

81. Arroll B, Goodyear-Smith F, Crengle S, Gunn J, Kerse N, Fishman T, Hatcher S. Validation of PHQ-2 and PHQ-9 to screen for major depression in the primary care population. Ann Fam Med. 2010;8(4):348-53. https://doi.org/10.1370/afm.1139.
82. Washburn RA, Smith KW, Jette AM, Janney CA. The physical activity scale for the elderly (PASE): development and evaluation. J Clin Epidemiol. 1993;46(2):153-62.

83. Russell DW. UCLA loneliness scale (version 3): reliability, validity, and factor structure. J Pers Assess. 1996;66(1):20-40.

84. Tinetti M, Richman D, Powell L. Falls Efficacy as a measure of fear of falling. J Gerontol. 1990;45(6):P239-43. https://doi.org/10. 1093/geronj/45.6.P239.

85. Ferrell BA, Stein WM, Beck JC. The geriatric pain measure: validity, reliability and factor analysis. J Am Geriatr Soc. 2000;48(12): 1669-73.

86. Desmond DW, Tatemichi TK, Hanzawa L. The telephone interview for cognitive status (TICS): reliability and validity in a stroke sample. Int J Geriatr Psychiatry. 1994;9(10):803-7.

87. Gerst-Emerson K, Jayawardhana J. Loneliness as a public health issue: the impact of loneliness on health care utilization among older adults. Am J Public Health. 2015;105(5):1013-9.

88. Rogers WA, Mitzner TL. Envisioning the future for older adults: autonomy, health, well-being, and social connectedness with technology support. Futures. 2017;87:133-9. https://doi.org/10.1016/j. futures.2016.07.002.

89. Leo M, Medioni G, Trivedi M, Kanade T, Farinella G. Computer vision for assistive technologies. Comput Vis Image Unders. 2016;148:1-5.

90. Zhang L, Leung H, Chan KC. Information fusion based smart home control system and its application. IEEE Trans Consum Electron. 2008;54(3):1157-65.

91. Dahmen J, Thomas B, Cook D, Wang X. Activity learning as a foundation for security monitoring in smart homes. Sensors. 2017;17(4):737. https://doi.org/10.3390/s17040737.

92. Zheng H, Wang H, Black N.Human activity detection in smart home environment with self-adaptive neural networks. In: Proceedings of the IEEE international conference on networking, sensing and control (ICNSC); 2008. pp. 1505-1510.

93. $\mathrm{Lu} \mathrm{CH}, \mathrm{Fu} \mathrm{LC}$. Robust location-aware activity recognition using wireless sensor network in an attentive home. IEEE Trans Autom Sci Eng. 2009;6:598-609.

94. Kim E, Helal S, Cook D. Human activity recognition and pattern discovery. IEEE Pervasive Comput. 2010;9:48-53.

95. Alirezaie M, Renoux J, Köckemann U, Kristoffersson A, Karlsson L, Blomqvist E, Tsiftes N, Voigt T, Loutfi A. An ontology-based context-aware system for smart homes: E-care@home. Sensors. 2017;17(1586):1-23. https://doi.org/10.3390/s17071586.

96. Gopalratnam K, Cook DJ. Online sequential prediction via incremental parsing: the active LeZi algorithm. IEEE Intell Syst. 2007;22:52-8.

97. Rogers WA, Fisk AD. Toward a psychological science of advanced technology design for older adults. J Gerontol Psychol Sci. 2010;65B:645-53. PMCID: PMC295433

Publisher's note Springer Nature remains neutral with regard to jurisdictional claims in published maps and institutional affiliations. 